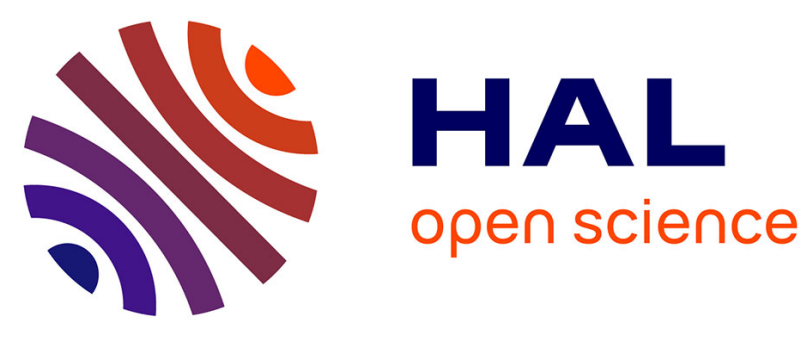

\title{
Host-Guest Binding Hierarchy within Redox- and Luminescence-Responsive Supramolecular Self-Assembly Based on Chalcogenide Clusters and $\gamma$-Cyclodextrin
} Anton A Ivanov, Clement Falaise, Pavel A Abramov, Michael A Shestopalov, Kaplan Kirakci, Kamil Lang, Mhamad A Moussawi, Maxim N Sokolov, Nikolay G Naumov, Sébastien Floquet, et al.

\section{To cite this version:}

Anton A Ivanov, Clement Falaise, Pavel A Abramov, Michael A Shestopalov, Kaplan Kirakci, et al.. Host-Guest Binding Hierarchy within Redox- and Luminescence-Responsive Supramolecular SelfAssembly Based on Chalcogenide Clusters and $\gamma$-Cyclodextrin. Chemistry - A European Journal, 2018, 24 (51), pp.13467-13478. 10.1002/chem.201802102 . hal-01863768

HAL Id: hal-01863768

https://hal-univ-rennes1.archives-ouvertes.fr/hal-01863768

Submitted on 29 Aug 2018

HAL is a multi-disciplinary open access archive for the deposit and dissemination of scientific research documents, whether they are published or not. The documents may come from teaching and research institutions in France or abroad, or from public or private research centers.
L'archive ouverte pluridisciplinaire HAL, est destinée au dépôt et à la diffusion de documents scientifiques de niveau recherche, publiés ou non, émanant des établissements d'enseignement et de recherche français ou étrangers, des laboratoires publics ou privés. 


\title{
Host-Guest Binding Hierarchy within Redox- and Luminescence Responsive Supramolecular Self-Assembly Based on Chalcogenide Clusters and $\gamma-$ Cyclodextrin
}

\author{
Anton A. Ivanov, ${ }^{[a, b, c]}$ Clément Falaise, ${ }^{[c]}$ Pavel A. Abramov, ${ }^{*[a, d]}$ Michael A. Shestopalov, $\left.{ }^{[a, b}, d\right]$ Kaplan \\ Kirakci, ${ }^{[e]}$ Kamil Lang, ${ }^{[e]}$ Mhamad A. Moussawi, ${ }^{[c]}$ Maxim N. Sokolov, ${ }^{[a,}$ d] Nikolay G. Naumov, ${ }^{[a,}$ d] \\ Sébastien Floquet, ${ }^{[c]}$ David Landy, ${ }^{[f]}$ Mohamed Haouas, ${ }^{*[c]}$ Konstantin A. Brylev, ${ }^{[a, d]}$ Yuri V. Mironov, ${ }^{[a, d]}$ \\ Yann Molard, ${ }^{[g]}$ Stéphane Cordier ${ }^{[g]}$ and Emmanuel Cadot ${ }^{*[c]}$
}

\begin{abstract}
Water-soluble salts of anionic $\left[\operatorname{Re}_{6} Q_{8}(C N)_{6}\right]^{4-}(Q=S$, Se, Te) chalcogenide octahedral rhenium clusters react with $\gamma$ cyclodextrin $(\gamma-C D)$ producing a new type of inclusion compounds. Crystal structures determined through single-crystal $X$-ray diffraction analysis revealed supramolecular host-guest assemblies resulting from close encapsulations of the octahedral cluster within two $\gamma$-CDs. Interestingly, nature of the inner $Q$ ligands influences strongly the host-guest conformation. The cluster $\left[\operatorname{Re}_{6} S_{8}(C N)_{6}\right]^{4}$ interacts preferentially with the primary faces of the $\gamma-C D$ while the bulkier clusters $\left[\mathrm{Re}_{6} \mathrm{Se}_{8}(\mathrm{CN})_{6}\right]^{4}$ and $\left[\mathrm{Re}_{6} \mathrm{Te}_{8}(\mathrm{CN})_{6}\right]^{4-}$ exhibit specific interactions with the secondary faces of the cyclic host. Furthermore, analysis of the crystal packing reveals additional supramolecular interactions that lead to $2 D$ infinite arrangements with $\left[\operatorname{Re}_{6} S_{8}(C N)_{6}\right]^{4}$ or to $1 D$ "bamboo-like" columns with $\left[\mathrm{Re}_{6} \mathrm{Se}_{8}(\mathrm{CN})_{6}\right]^{4-}$ and $\left[\mathrm{Re}_{6} \mathrm{Te}_{8}(\mathrm{CN})_{6}\right]^{4}$ species. Solution studies, using multinuclear NMR methods, ESI-MS and Isothermal titration calorimetry (ITC) corroborates nicely the solid state investigations showing that supramolecular pre-organization is retained in aqueous solution
\end{abstract}

[a] A. A. Ivanov, Dr. P. A. Abramov, Dr. M. A. Shestopalov, Prof. Dr. M. N. Sokolov, Dr. N. G. Naumov, Dr. K. A. Brylev, Dr. Y. V. Mironov Nikolaev Institute of Inorganic Chemistry SB RAS

3 acad. Lavrentiev ave., 630090 Novosibirsk (Russia)

E-mail: abramov@niic.nsc.ru

[b] A. A. Ivanov, Dr. M.A. Shestopalov

The Federal Research Center of Fundamental and Translational Medicine

2 Timakova st., 630117 Novosibirsk (Russia)

[c] A. A. Ivanov, Dr. C. Falaise, Dr. M. A. Moussawi, Dr. S. Floquet, Dr. M. Haouas, Prof. Dr. E. Cadot

Institut Lavoisier de Versailles, CNRS, UVSQ, Université Paris Saclay

45 avenue des Etats-Unis, 78035 Versailles (France)

E-mail: emmanuel.cadot@uvsq.fr, mohamed.haouas@uvsq.fr

[d] Dr. P. A. Abramov, Dr. M. A. Shestopalov, Prof. Dr. M. N. Sokolov, Dr. N. G. Naumov, Dr. K. A. Brylev, Dr, Y. V. Mironov Novosibirsk State University

2 Pirogova st., 630090 Novosibirsk (Russia)

[e] Dr. K. Kirakci, Prof. K. Lang

Institute of Inorganic Chemistry of the Czech Academy of Sciences

Husinec-Řež 1001, 25068 Řež (Czech Republic)

[f] Prof. D. Landy

Unité de Chimie Environnementale et Interactions sur le Vivant (UCEIV, EA 4492)

145, Avenue Maurice Schumann, MREI 1, 59140 Dunkerque (France)

[g] Dr. Y. Molard, Dr. S. Cordier

Institut des Sciences Chimiques de Rennes, UMR 6226 CNRS Université de Rennes 1

Avenue du Général Leclerc, 35042 Rennes (France)

Supporting information for this article is given via a link at the end of the document. even in diluted conditions. Furthermore, ITC analysis showed that host-guest stability increases significantly ongoing from $S$ to Te. At last, we report herein that deep inclusion alters significantly the intrinsic physical-chemical properties of the octahedral clusters, allowing redox tuning and near IR luminescence enhancement.

\section{Introduction}

Self-assembly processes and structures driven by weak noncovalent interactions give rise to innumerable chemical events in living organisms. ${ }^{[1]}$ Resulting supramolecular organizations are of prime importance in functioning compartmentalized systems such as enzymes which conjugate sophisticated structures with highly specific molecular recognition involved within cascade catalytic mechanisms. ${ }^{[2]}$ Thereby, self-assembly in biological systems have been often used as guiding models for designing "bio-inspired" sophisticated supramolecular complexes. Such a biomimicking approach has led to many efficient innovative systems in the field of artificial photosynthesis, ${ }^{[3]}$ catalysis ${ }^{[4]}$ or drug delivery. ${ }^{[5]}$

Actually, development of new composite materials by controlling nature, specificity and strength of intermolecular interactions corresponds to an efficient strategy for the design of hierarchical hybrid assemblies with novel structures and emergent properties. ${ }^{[6]}$ In this context, host-guest type supramolecular arrangements are of particular interest, especially those that use cyclodextrins (CDs) as functional cavitand. Cyclodextrins are symmetrical macrocyclic cavitands consisting of six, seven, or eight glucopyranoside units named $\alpha-, \beta-$, or $\gamma-C D$, respectively. ${ }^{[7]}$ Due to their crown-like hydrophilic portals and hydrophobic inner cavity, CDs have received much interest as host receptors in encapsulation processes and hybrid assemblies. ${ }^{[5 b, 8]}$ Their remarkable structural features have led to wide applications in separation, analysis, selective catalysis, materials and life sciences. ${ }^{[9]}$ Moreover, impressive inclusion capabilities and resulting synthetic host-guest systems create favorable conditions for substrate activation in the hydrophobic cavities of CDs via non-covalent interactions, thus mimicking enzymatic chemical reactions. ${ }^{[9 b]}$ Usually such bioinspired systems involve coordination ${ }^{[10]}$ or organometallic ${ }^{[11]}$ complexes closely embedded within the hydrophobic pocket of CDs. Nevertheless, little is known about supramolecular interactions of CDs with polynuclear species, such as metal clusters. Recently inclusion complexes with polyoxometalates ${ }^{[12]}$ and octahedral clusters ${ }^{[12 b, 13]}$ were reported. Their structural investigations clearly demonstrate that stoichiometry, 


\section{FULL PAPER}

conformation and spatial arrangement of the resulting host-guest adducts are highly sensitive to the nature of the guest, leading to highly contrasted behavior in solution, ranging from extremely labile assembly with $\left[\mathrm{Re}_{6} \mathrm{~S}_{8}\left(\mathrm{H}_{2} \mathrm{O}\right)_{6}\right]^{2+}$ up to dynamically frozen supramolecular arrangement with $\left[\mathrm{Ta}_{6} \mathrm{Br}_{12}\left(\mathrm{H}_{2} \mathrm{O}\right)_{6}\right]^{2+}$ species. ${ }^{[12 b}$, 13a] For instance, encapsulation of the $\left[\mathrm{Ta}_{6} \mathrm{Br}_{12}\left(\mathrm{H}_{2} \mathrm{O}\right)_{6}\right]^{2+}$ cluster within two $\gamma$-CD molecules provokes spectacular changes in the redox potential, thereby showing that physical-chemical properties of the cluster are highly sensitive to its proximal environment even in the absence of specific coordinative interactions. In this context, supramolecular host-guest systems involving cluster-based assemblies and CDs are of prime interest in biology or medicine. Actually, electron-rich octahedral clusters exhibit highly appealing optical properties such as phosphorescence in the NIR region triggered by UV, visible light or even X-ray irradiation ${ }^{[14]}$ with lifetimes up to several hundred microseconds and exceptionally high quantum yield, making this class of material highly relevant for bioimaging ${ }^{[15]}$ or biolabelling applications. ${ }^{[16]}$ Additionally, this class of compounds exhibit high radiodensity due to close packing of heavy elements in the cluster core $\left\{M_{6} Q_{8}\right\}$ with $M=M o, W$ or Re; $Q=S e, T e, B r$ or $I$ which is a pre-requisite for $\mathrm{X}$-ray contrast agents and thereby useful for bimodal bioimaging. ${ }^{[17]}$ Moreover, octahedral clusters behave also as potential antitumoral and antimicrobial agents due to their ability to generate singlet oxygen upon photoirradiation. ${ }^{[18]}$ Thus, cumulative properties such as luminescence, redox activity, amenability to unique chemical transformations make this class of multifunctional compounds highly relevant for the design of efficient bioactive systems. As cyclodextrins are well-known to improve biocompatibility and bioavailability of drug molecules, ${ }^{[19]}$ their combination with $\left\{M_{6} Q_{8}\right\}$ octahedral based-clusters paves the way toward a novel class of agents highly relevant for bioimaging, diagnostic or therapy. a)
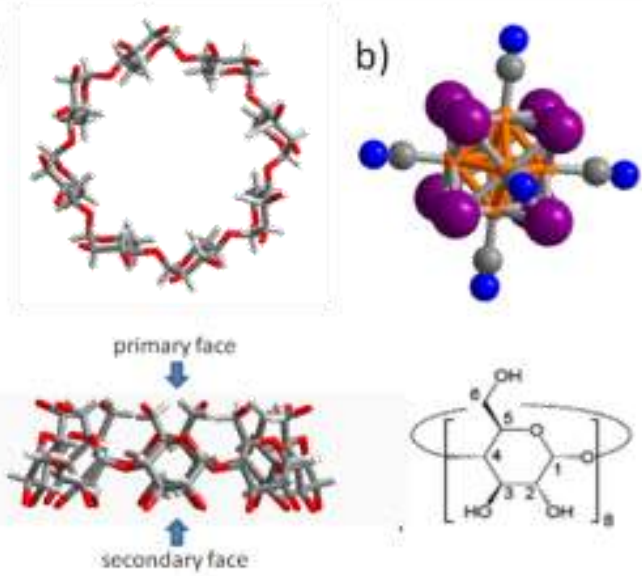

Figure 1. Structural representation of the molecular components used as building blocks: a) $\gamma$-cyclodextrin $\mathrm{C}_{48} \mathrm{H}_{80} \mathrm{O}_{40} \quad(\gamma$-CD) resulting from the condensation of eight glycopyranose units $\left\{\mathrm{C}_{6} \mathrm{H}_{10} \mathrm{O}_{5}\right\}$. The macrocycle delimits the primary face (lined by the eight methanolic groups) and by the opposite secondary face (lined by sixteen hydroxyl groups). b) octahedral cluster $\left[\mathrm{Re}_{6} \mathrm{Q}_{8}(\mathrm{CN})_{6}\right]^{4-}$ built from six rhenium $\mathrm{Re}^{\mathrm{III}}$ ions located at the octahedron corners and mutually linked through metal-metal bonds ( $R e-R e=2.64-2.69 \AA)$. The resulting $\left\{\mathrm{Re}_{6}\right\}$ core is face capped by eight $\mu_{3}-\mathrm{Q}$ ligands (with $\mathrm{Q}=\mathrm{S}$, Se and $\mathrm{Te}$ ) while the coordination sphere of the six Re centers is completed by a cyano ligand in apical position. Color code: orange $=$ rhenium, violet $=Q(S$, Se or Te), grey = carbon, blue = nitrogen, red = oxygen, white = hydrogen .
In this paper we report on the formation of host-guest supramolecular complexes in aqueous solution involving $\gamma$-CD as host and anionic $\left[\operatorname{Re}_{6} \mathrm{Q}_{8}(\mathrm{CN})_{6}\right]^{4-}(\mathrm{Q}=\mathrm{S}$, Se, Te) clusters as guests (Figure 1). Structural models of supramolecular adducts have been obtained through single-crystal $\mathrm{X}$-ray diffraction analysis, revealing the deep inclusion of the $\left[\operatorname{Re}_{6} Q_{8}(C N)_{6}\right]^{4-}$ clusters within two $\gamma$-CD capsules. Furthermore, solution studies, using ESI-MS and multinuclear NMR techniques confirmed that supramolecular interactions are maintained in aqueous solution. Nevertheless, isothermal titration calorimetry experiments (ITC) revealed that efficiency of the supramolecular recognition process is strongly dependent upon the nature of the $\mu_{3}$ chalcogenide ion $(\mathrm{Q}=\mathrm{S}$, Se or $\mathrm{Te})$ in the $\left\{\mathrm{Re}_{6} \mathrm{Q}_{8}\right\}^{2+}$ cluster core. Such a contrasting behavior is also nicely supported by NMR conclusions that balance from highly labile associations with $Q=$ $S$, Se to robust frozen arrangements with $Q=T e$. Besides, we report herein that supramolecular $\gamma$-CD shells have noteworthy influences upon the electrochemical and luminescence properties of the embedded clusters, thus providing new arguments and opportunities for their deliberate integration within functioning systems useful in the area of biotechnological applications.

\section{Results and Discussion}

\section{Formation of the $\gamma$-CD based adducts}

Isolation of the supramolecular adducts has been carried out through systematic studies using different ratios of alkali salts of octahedral clusters $\mathrm{M}_{4}\left[\mathrm{Re}_{6} \mathrm{Q}_{8}(\mathrm{CN})_{6}\right] \cdot \mathrm{nH}_{2} \mathrm{O}$ (with $\mathrm{M}=\mathrm{Na}$ or $\mathrm{K}$ and $\mathrm{Q}=\mathrm{S}$, Se or $\mathrm{Te}$ ) and varying procedures of crystallization such as slow evaporation of aqueous solution or vapor diffusion method. In short, this study showed that Se- and Te-containing clusters exhibit high propensity to form the 1:2 supramolecular adduct $\left\{\operatorname{Re}_{6} \mathrm{Q}_{8}\right\} \subset(\gamma-C D)_{2}$, consistent with $\mathrm{X}$-Ray diffraction analysis or NMR solution studies. Compounds $\mathbf{1}$ and $\mathbf{2}$ corresponding to $\mathrm{Na}_{4}\left\{\left[\operatorname{Re}_{6} \mathrm{Te}_{8}(\mathrm{CN})_{6}\right] \subset(\gamma-\mathrm{CD})_{2}\right\} \cdot(\gamma-\mathrm{CD}) \cdot 30 \mathrm{H}_{2} \mathrm{O}$ and $\mathrm{K}_{4}\left\{\left[\mathrm{Re}_{6} \mathrm{Se}_{8}(\mathrm{CN})_{6}\right] \subset(\gamma-\mathrm{CD})_{2}\right\} \cdot(\gamma-\mathrm{CD}) \cdot 40 \mathrm{H}_{2} \mathrm{O}$, respectively, were obtained as single-crystals through slow evaporation of aqueous solutions. Conversely, applying similar procedures to the sulfurcontaining cluster unit led systematically to formation of colorless cluster-free crystals corresponding to $\gamma$-CD, meaning that supramolecular interactions should give labile and highly soluble adducts reluctant to crystallize. Nevertheless, changing the crystallization conditions for slow ethanol vapor diffusion into aqueous solution containing cesium chloride produced singlecrystals suitable for $\mathrm{XRD}$. Structural analysis of compound $\mathrm{Cs}_{4} \mathrm{~K}_{8}\left\{\left[\mathrm{Re}_{6} \mathrm{~S}_{8}(\mathrm{CN})_{6}\right] \subset(\gamma-\mathrm{CD})_{2}\right\} \cdot 2\left[\mathrm{Re}_{6} \mathrm{~S}_{8}(\mathrm{CN})_{6}\right] \cdot 2(\gamma-\mathrm{CD}) \cdot 49 \mathrm{H}_{2} \mathrm{O}$ revealed unexpected host-guest interactions as discussed below.

\section{Single-crystal X-ray analysis}

Main crystallographic parameters for structures of compounds $\mathbf{1}$, 2 and 3 which involves $\gamma$-cyclodextrin and $\left[\operatorname{Re}_{6} Q_{8}(C N)_{6}\right]^{4-}$ with $Q$ $=\mathrm{Te}$, Se or $\mathrm{S}$, respectively, are given in supporting information (SI §2.1, Table S1). X-ray diffraction study revealed three hostguest supramolecular adducts involving $\gamma$-CD and octahedral clusters $\left[\operatorname{Re}_{6} Q_{8}(C N)_{6}\right]^{4-}$ with $Q=T e$, Se or $S$. Nevertheless, depending upon conditions of crystallization and the nature of the octahedral-type cluster, CD:cluster stoichiometry and supramolecular interactions observed in the crystal structures differ strikingly. 
a)

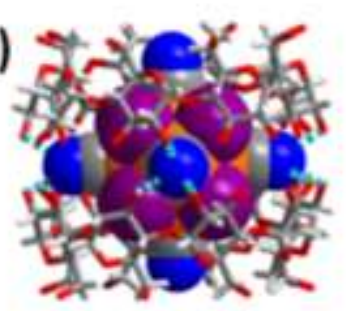

c)

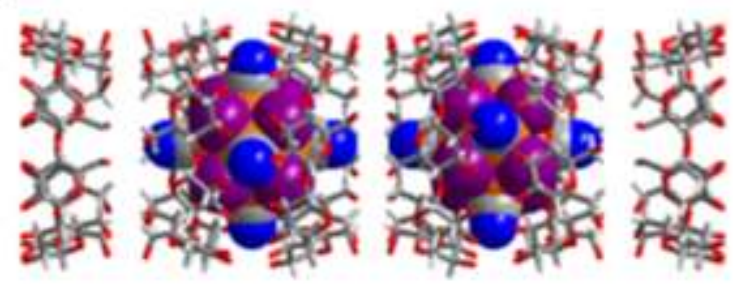

Figure 2. Mixed representations of the solid state structure of the supramolecular host-guest $\left\{\left[\operatorname{Re}_{6} Q_{8}(C N)_{6}\right] \subset(\gamma-C D)_{2}\right\}^{4-}$ complex with $Q=S e$ or Te: a) side view showing the hydrogen bonding between the equatorial cyano groups and the hydroxyls of the primary faces of the CDs; b) top view highlighting close interactions between inner $\mathrm{H}-3$ hydrogen (pale-green sphere) and four $Q$ ligands (violet sphere) with $H \cdots Q=3.1-3.5 \AA$; $)$ focus on the linear "bamboo-like" arrangement running along $c$ axis.

Structural analysis of $\mathrm{Na}_{4}\left\{\left[\mathrm{Re}_{6} \mathrm{Te}_{8}(\mathrm{CN})_{6}\right] \subset(\gamma-\mathrm{CD})_{2}\right\} \cdot(\gamma-\mathrm{CD}) \cdot 30 \mathrm{H}_{2} \mathrm{O}$ and $\mathrm{K}_{4}\left\{\left[\mathrm{Re}_{6} \mathrm{Se}_{8}(\mathrm{CN})_{6}\right] \subset(\gamma-\mathrm{CD})_{2}\right\} \cdot(\gamma-\mathrm{CD}) \cdot 40 \mathrm{H}_{2} \mathrm{O}$ (noted 1 and 2, respectively) revealed two isostructural compounds which contain the octahedral cluster $\left[\operatorname{Re}_{6} \mathrm{Q}_{8}(\mathrm{CN})_{6}\right]^{4-}$ closely embedded into two $\gamma$-CDs facing their wider rim (secondary face) and $\left\{\mathrm{Re}_{6} \mathrm{Q}_{8}\right\}^{2+}$ clusters range within those usually observed (see SI §2.2, Table S2). In addition, some weak intermolecular interacting mutually through hydrogen bonds $(\mathrm{O} \cdot \cdots \mathrm{O} \sim 2.8-3.1 \AA)$ (see Figure 2a). Geometrical parameters of the encapsulated $\left\{\mathrm{Re}_{6} \mathrm{Q}_{8}\right\}^{2+}$ clusters range within those usually observed (see $\mathrm{SI}$ \$2.2, Table S2). In addition, some weak intermolecular interactions can be identified within the solid state structures contributing to the stability of the supramolecular host-guest arrangements. Each equatorial cyano group interacts through hydrogen bonds with the three closest hydroxo groups of the wider rim of $C D$ giving $\mathrm{N} \cdots \mathrm{O}$ distances in the 2.8-3.0 $\AA$ range while $Q$ inner ligands $(Q=S e$ or $T e)$ participate also to the supramolecular cohesion (see Figures 2a-b), giving close contacts with inward-directed hydrogen $\mathrm{H}-3$ labelled in the $\gamma-\mathrm{CD}$ $(\mathrm{H} \cdots \cdot \mathrm{Se}=3.2-3.5 \AA$ and $\mathrm{H} \cdots \cdot \mathrm{Te}=3.1-3.4 \AA)$. Furthermore, in the crystal packing, two supramolecular adducts $\left\{\left[\operatorname{Re}_{6} \mathrm{Q}_{8}(\mathrm{CN})_{6}\right] \subset(\gamma\right.$ $\left.\mathrm{CD})_{2}\right\}^{4-}$ stack together through their primary faces along the [001] direction to give the typical tubular arrangement. At last, both sides are symmetrically closed by two additional free $\gamma$-CDs (see Figure 2c). The cohesion within such large enchainment is mainly ensured by a network of direct hydrogen bonding that interconnects alternately secondary rims and primary rims $(\mathrm{O} \cdots \mathrm{O}=2.7-3.0 \AA)$. This arrangement appears very similar to that reported previously by $\mathrm{Nau}$ et al. on inclusion complexes involving $\gamma-\mathrm{CD}$ and $\left[\mathrm{B}_{12} \mathrm{Br}_{12}\right]^{2-}$ dodecaborate cluster. ${ }^{[20]}$ Such similarities mean that in this case, crystal packing is mainly imposed by structural properties of the bulky $\gamma-C D$, while water molecules and disordered counter-cations $\left(\mathrm{Na}^{+}\right.$or $\mathrm{K}^{+}$for $\mathrm{Q}=\mathrm{Se}$

or Te, respectively) should be probably distributed within large voids between the tubular assemblies.

X-ray diffraction structural analysis of compound $\mathbf{3}$ containing the $\left[\mathrm{Re}_{6} \mathrm{~S}_{8}(\mathrm{CN})_{6}\right]^{4-}$ octahedral type-cluster and $\gamma-\mathrm{CD}$ is graphically shown in Figure 3. Crystal structure of $\mathbf{3}$ reveals also host-guest arrangements built on the cluster unit bicapped by two $\gamma$-CD molecules, but here, both $\gamma$-CD face their two primary faces (see Figure 3a), instead of the secondary faces as observed in structure $\mathbf{1}$ and $\mathbf{2}$. It should be worth remarking that such host-guest disposition was already reported in systems involving bulky guests such as Keggin $\left[\mathrm{PMo}_{12} \mathrm{O}_{40}\right]^{3-}$ or Dawson $\left[\mathrm{P}_{2} \mathrm{~W}_{18} \mathrm{O}_{62}\right]^{6-}$ anions. ${ }^{[12 \mathrm{a}, 12 \mathrm{c}]}$ Furthermore, the relative disposition of the cluster within the two opposite CDs depicted in $\mathbf{3}$ differs from that observed in $\mathbf{1}$ or $\mathbf{2}$. The equatorial plane of the $\left[\mathrm{Re}_{6} \mathrm{~S}_{8}(\mathrm{CN})_{6}\right]^{4-}$ cluster lined by four in plane cyano groups is perpendicularly directed with respect to the faces of the $\gamma$-CDs while the two remaining opposite axial cyano ligands point between the two primary rings of the $\gamma$-CDs. Nonetheless, complete structural description of crystal $\mathbf{3}$ should mention an additional type of interactions wherein the cluster unit and $\gamma$-CD stack together to form regular planes (see Figure $3 b$ ). In such arrangement the cavity of $\gamma$-CD remains free while the clusters interact with the outer part of $\gamma-C D$ torus (see Figure $3 b$ ). In summary, compound $\mathbf{3}$ exhibits an overall stoichiometry cluster: $\gamma-C D=3: 4$ and contains two types of supramolecular interactions, leading to a quite typical $1: 2$ discrete host-guest arrangement involving the primary faces of the $\gamma$-CD tori. The second type of interaction appears less specific and allows the formation of regular plane paved from the strict alternation of $\left[\mathrm{Re}_{6} \mathrm{~S}_{8}(\mathrm{CN})_{6}\right]^{4-}$ anion and $\gamma$-CD tori. At last, the counter cations, $\mathrm{K}^{+}$and $\mathrm{Cs}^{+}$, have been found and appear mainly located in the vicinity of the hydroxyl groups of the $\gamma$-CD and, thereby, quite far from the anionic clusters (not shown).
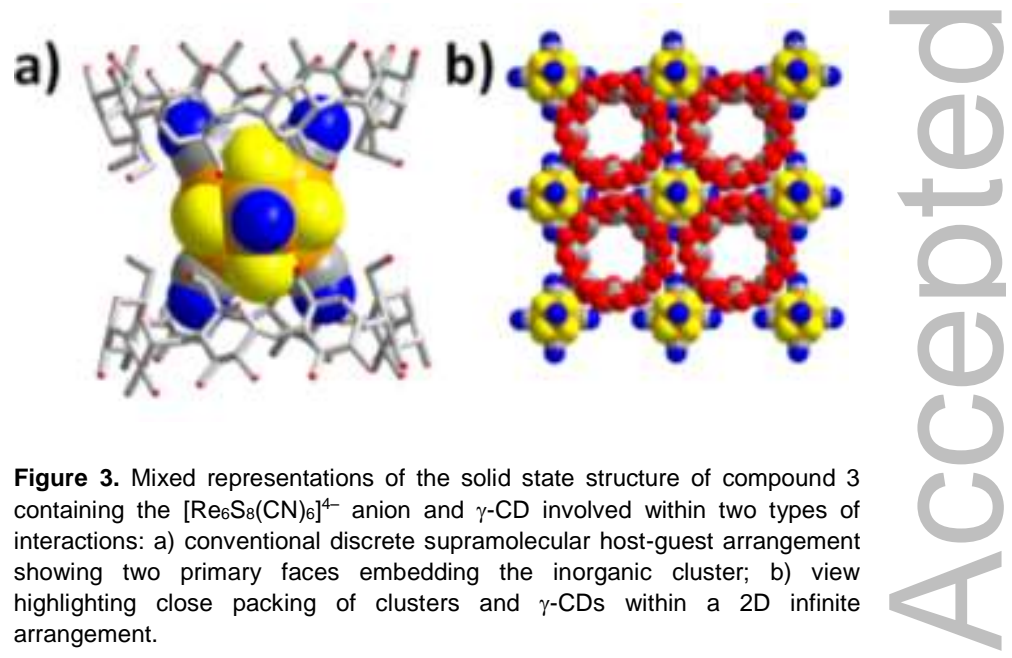

Figure 3. Mixed representations of the solid state structure of compound 3 containing the $\left[\operatorname{Re}_{6} \mathrm{~S}_{8}(\mathrm{CN})_{6}\right]^{4-}$ anion and $\gamma-\mathrm{CD}$ involved within two types of interactions: a) conventional discrete supramolecular host-guest arrangement showing two primary faces embedding the inorganic cluster; b) view highlighting close packing of clusters and $\gamma$-CDs within a 2D infinite arrangement.

\section{Solution studies}

The solution behavior was investigated by a set of complementary techniques such as multinuclear ${ }^{11} \mathrm{H},{ }^{13} \mathrm{C},{ }^{77} \mathrm{Se}$ and ${ }^{125}$ Te NMR spectroscopy, UV-Vis spectroscopy, ITC, and ESI-mass spectrometry. ITC experiments were conducted to determine the thermodynamic parameters of the encapsulation process. 


\section{FULL PAPER}

\section{NMR study}

Multinuclear NMR provides complementary informative analytical tools able to track supramolecular effects using available NMR probes either from the host $\left({ }^{1} \mathrm{H}\right.$ or $\left.{ }^{13} \mathrm{C}\right)$ or from the guests with ${ }^{77} \mathrm{Se}$ and ${ }^{125} \mathrm{Te} \cdot{ }^{[21]}{ }^{1} \mathrm{H}$ NMR titrations were conducted for all clusters $Q=S$, Se or Te allowing to determine averaged cluster:CD stoichiometry in solution (Job plot analysis) and in some extend to give some insights about structures of supramolecular aggregates formed in aqueous solutions. ${ }^{1} \mathrm{H}$ NMR titrations are shown in Figures $4 \mathrm{a}-\mathrm{c}$, and experimental details given in supporting information section. In the case of Tecontaining cluster (Figure 4a), appearance of several new signals feature complex formation in a nearly frozen situation on the NMR time scale. For instance, $\mathrm{H} 1$ and $\mathrm{H} 5$ resonances clearly reflect the formation of the 1:2 host-guest arrangement in aqueous solution (see Figure 4a). Nevertheless, combination of slow exchange dynamics and restricted molecular movement due to aggregation cause significant line broadening (see, SI $\S 3.1$, Figure S2). In case of $\mathrm{S}$ or Se clusters, ${ }^{1} \mathrm{H}$ NMR patterns behave differently, without excessive line broadening upon introducing up to 12 cluster equivalents (see Figures $4 \mathrm{~b}$ and $4 \mathrm{c}$ ), concomitant with the gradual variations of the ${ }^{1} \mathrm{H}$ NMR resonances. These results are consistent with highly labile associations (extreme narrowing situation on the NMR time scale). These observations confirm quite strong interaction of the three clusters $(Q=T e$, Se or $S)$ with the $\gamma$-CD torus which should correspond to inclusion complexes.

For Te- and Se-containing clusters, most important shifts for the inner H3 protons supported by NMR titration and Job plot analysis appear fairly consistent with the solid state structure $\mathbf{3}$ showing the $\left\{\left[\operatorname{Re}_{6} \mathrm{Q}_{8}(\mathrm{CN})_{6}\right] \subset(\gamma-\mathrm{CD})_{2}\right\}^{4-}$ arrangement (see Figure 2a). In addition, the existence of the 1:2 supramolecular arrangements in diluted solutions has been confirmed by ITC experiments. For the S-containing cluster, NMR analysis shows clearly that in addition to $\mathrm{H} 3$ chemical shift variations, $\mathrm{H} 5$ inner proton appears also mostly affected by the inclusion process. Besides, NMR analysis is also consistent with 1:1 average stoichiometry nicely confirmed by ITC (see SI § 3.2, Figures S3 and S4a). As these results differ from those obtained from X-ray diffraction analysis (see Figure 3), they could arise from weak selectivity of the supramolecular recognition process due to the smaller sized sulfur-containing cluster. Size volume calculation within the $\left[\operatorname{Re}_{6} \mathrm{Q}_{8}(\mathrm{CN})_{6}\right]^{4-}$ series gives 387,419 and $473 \AA^{3}$ for $\mathrm{Q}$ $=\mathrm{S}$, Se and Te, respectively. Weak selectivity and affinity (see ITC results below) lead to predominant $1: 1$ associations in solution that could occur either from the secondary face (affecting the $\mathrm{H} 3$ inner proton) or from the primary face of the torus (leading to the $\mathrm{H} 5$ shift resonance).

Evidence for the inclusion complex formation is also provided by ${ }^{1} \mathrm{H}$ DOSY NMR. The self-diffusion coefficient $D$ of $\gamma$-CD drops from ca. $250 \mu \mathrm{m}^{2} / \mathrm{s}$ for the free $\gamma-C D^{[21 b]}$ to ca. 220,210 , and 190 $\mu \mathrm{m}^{2} / \mathrm{s}$ for $\mathrm{CD}-\left[\operatorname{Re}_{6} \mathrm{Q}_{8}(\mathrm{CN})_{6}\right]^{4-}$ solutions for $\mathrm{Q}=\mathrm{S}$, Se, and Te respectively, upon increasing the cluster to $C D$ ratio (for further details, see SI, §3.3, Figure S5). However $D$ changes are moderate because the hydrodynamic radii of supramolecular adducts are dominated mainly by the CD host, but significant decreases of self-diffusion coefficients indicate formation of labile host-guest aggregates.

${ }^{77} \mathrm{Se}$ and ${ }^{125} \mathrm{Te}$ NMR studies of solutions containing $\left[\operatorname{Re}_{6} \mathrm{Q}_{8}(\mathrm{CN})_{6}\right]^{4-}(\mathrm{Q}=\mathrm{Se}, \mathrm{Te})$ and $\gamma$-CD have been conducted at
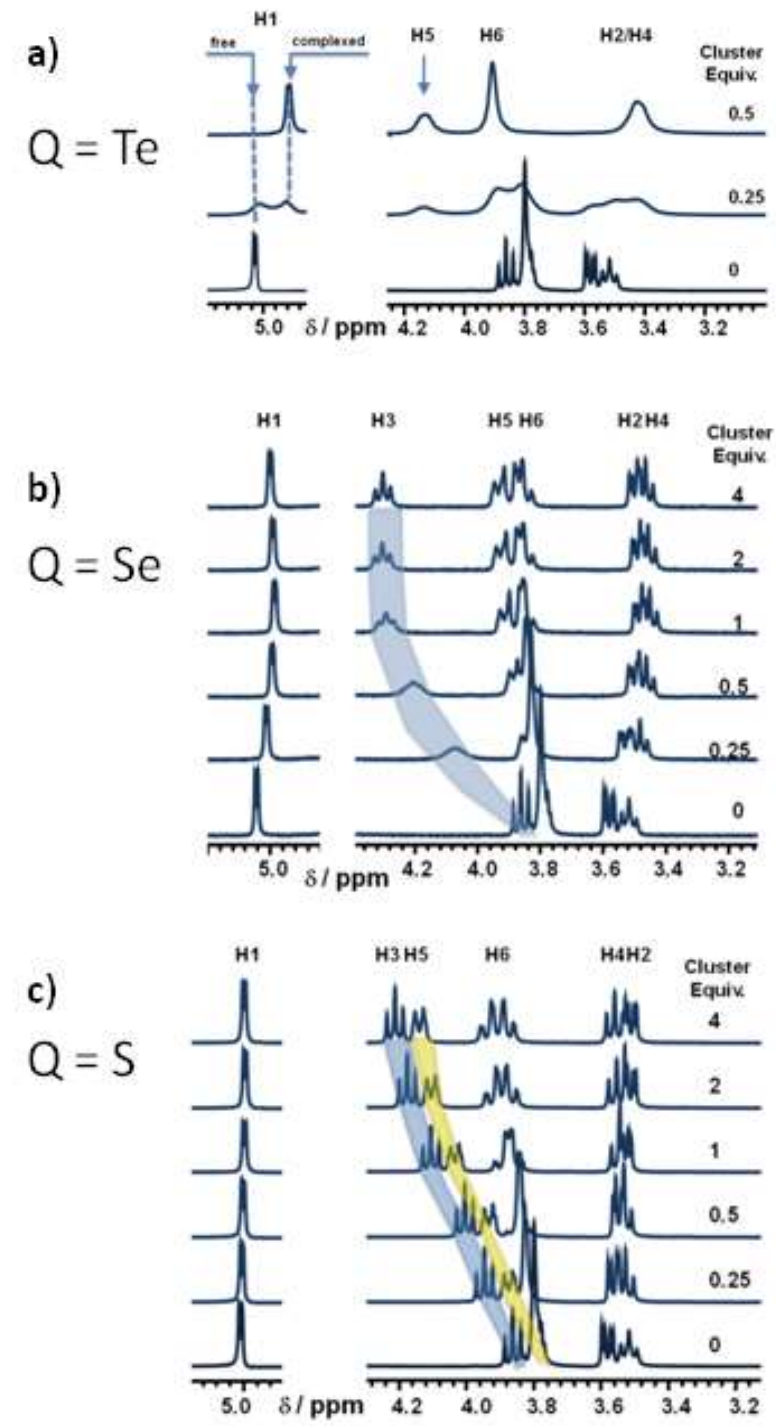

Figure 4. ${ }^{1} \mathrm{H}$ NMR spectra resulting of the titration of $3 \mathrm{mmol} \cdot \mathrm{L}^{-1}$ aqueous solution of $\gamma$-CD by $\left[\operatorname{Re}_{6} Q_{8}(C N)_{6}\right]^{4-}$ cluster. a) $Q=T e$; b) $Q=S e$ and c) $Q=S$.

fixed cluster concentration (shown in Figure 5). In the case of Se cluster, a single signal is observed shifting progressively from $\delta$ $=-389 \mathrm{ppm}$ to the limiting value at $-392.6 \mathrm{ppm}$ (see Figure 5b). This indicates a fast exchange regime between the different cluster species, i.e. solvated or embedded within $\gamma$-CD. Besides, Job plot using the ${ }^{77}$ Se NMR data (see SI, §3.2, Figure S3) confirms the formation of the predominant 1:2 type complex in aqueous solution, still consistent with the solid state structure and ${ }^{1} \mathrm{H}$ NMR analysis. Conversely, complexation of the $\left[\mathrm{Re}_{6} \mathrm{Te}_{8}(\mathrm{CN})_{6}\right]^{4-}$ cluster leads to two ${ }^{125} \mathrm{Te}$ NMR resonances at $\delta$ $=-1127 \mathrm{ppm}$ and $\delta=-1165 \mathrm{ppm}$ according to the slow chemical exchange regime observed by ${ }^{1} \mathrm{H}$ NMR. While ${ }^{125} \mathrm{Te}$ NMR titration gives also direct evidence for the 1:2 stoichiometry of the frozen CD-cluster conformation (see SI, §3.1 and 3.2, Figure S4b), such an experiment allows evidencing the formation of the highly labile $1: 1$ complex which causes the significant broadening of the $\delta=-1127 \mathrm{ppm}^{125} \mathrm{Te}$ resonances observed for $\mathrm{CD} /$ cluster ratio in the $0-1$ range (see Figure $5 \mathrm{a}$ ). 


\section{FULL PAPER}

a) ${ }^{125} \mathrm{Te}$ NMR
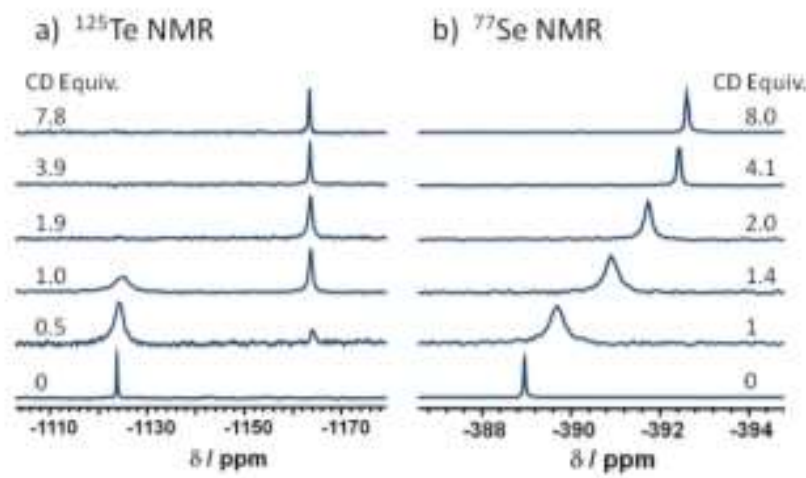

Figure 5. (a) ${ }^{125} \mathrm{Te} N \mathrm{NMR}$ spectra of $6 \mathrm{mM}$ solution of $\left[\mathrm{Re}_{6} \mathrm{Te}_{8}(\mathrm{CN})_{6}\right]^{4-}$ and (b) ${ }^{77} \mathrm{Se} N M R$ spectra of $24 \mathrm{mM}$ solution of $\left[\mathrm{Re}_{6} \mathrm{Se}_{8}(\mathrm{CN})_{6}\right]^{4-}$, containing various amounts of $\gamma$-CD.

At last, ${ }^{13} \mathrm{C}$ NMR spectra were also recorded to monitor the inclusion complex formation (see SI, §3.4, Figure S6) through the conformational changes of the $\gamma$-CD macrocycle. The spectra of Te cluster system showed broad signals due to slow exchange regime that makes the measurement and interpretation of the spectra difficult. However, narrow signals are obtained for $\mathrm{S}$ and $\mathrm{Se}$ cluster systems and their measurements are much easier. Actually, variations of ${ }^{13} \mathrm{C} N M R$ chemical shifts reflect mainly the macrocycle distortions when accommodating the guest rather than the through-space hostguest contacts, as observed with ${ }^{1} \mathrm{H}^{[21 b]}$ Featuring the mode of encapsulation, the carbon $\mathrm{C} 1$ and $\mathrm{C} 4$ atoms of the ring exhibit an opposite chemical shift variation (see SI, §3.4). These C1 and $\mathrm{C} 4$ atoms behave as hinge within the CD backbone, allowing in some extent expansion / contraction of the opposite rims. According to the solid state structure, host-guest interactions should provoke expansion of the secondary rim and the concomitant contraction of the primary one when $Q=S e$ while opposite trend holds for $Q=S$. It should be worth remarking that chemical shifts of the remaining $\mathrm{C} 2, \mathrm{C} 3, \mathrm{C} 5$ and C6 carbon atoms exhibits similar variation whatever the nature of the chalcogenide inner ligands $(Q=S$ or $S e)$. Furthermore, the ${ }^{13} \mathrm{C}$ NMR chemical shift of the outer cyano ligands appears quite unaffected for the sulfur-containing cluster while it undergoes significant deshielding when $Q=$ Se. Such $a$ difference arises probably from the hydrogen bonding network similar to that detected in the solid state which involves the equatorial cyano groups and the sixteen hydroxyl groups from the secondary rim (see Figure 2a). Such types of supramolecular interaction are prominent with the $\left[\mathrm{Re}_{6} \mathrm{Se}_{8}(\mathrm{CN})_{6}\right]^{4-}$ and fully cancelled in the host-guest conformations involving the S-containing cluster $\left[\mathrm{Re}_{6} \mathrm{~S}_{8}(\mathrm{CN})_{6}\right]^{4-}$ and the primary faces of the CDs (see Figure 3a).

\section{ESI-MS studies}

Solutions containing cluster and $\gamma-C D$ have been investigated using ESI-MS. The results corroborate entirely the hypotheses and interpretations formulated from solid state analysis and multinuclear NMR investigations. In each case, the ESI-MS spectrum contains the 1:1 and 1:2 supramolecular complexes (see SI, §4, Figure S7 for further details). For $\mathrm{Q}=\mathrm{S}$ or Se, the $1: 1$ and $1: 2$ adducts are associated to two $\mathrm{Na}^{+}$cations to give $\left\{\mathrm{Na}_{2}\left[\mathrm{Re}_{6} \mathrm{Q}_{8}(\mathrm{CN})_{6}\right] \subset(\gamma-\mathrm{CD})_{x}\right\}^{2-}$ species with $\mathrm{x}=1$ or 2 while for $\mathrm{Q}$

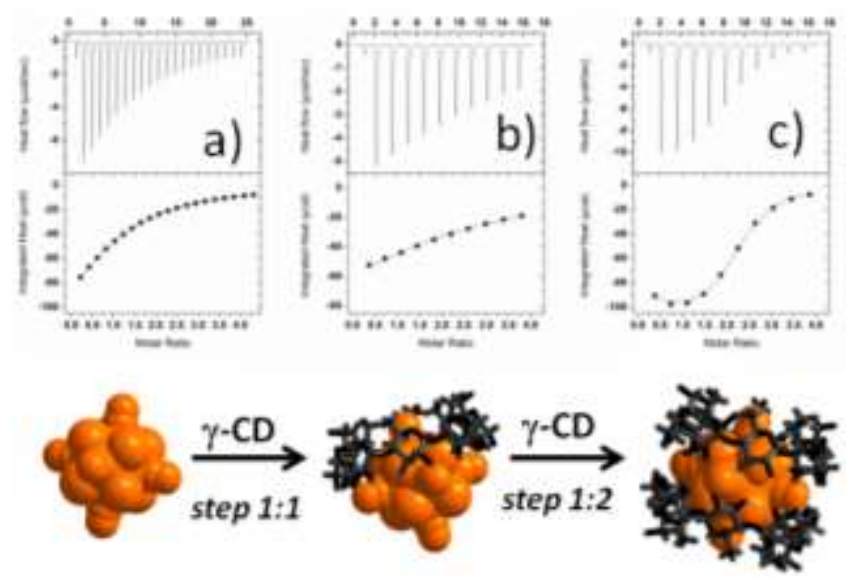

Figure 6. ITC thermograms (upper part) and isotherms (lower part) at $283 \mathrm{~K}$ corresponding to titration of solution of $\mathrm{K}_{4}\left[\operatorname{Re}_{6} \mathrm{Q}_{8}(C N)_{6}\right]$ by $\gamma-C D$ : a) $\mathrm{Q}=\mathrm{S}$; b) $\mathrm{Q}$ = Se and c) $Q=$ Te. They have been interpreted as the result of formation of $1: 1$ and $1: 2$ supramolecular adducts in two consecutive steps, except for $Q=$ $S$ where the 1:2 step was found negligible (see Table 1).

$=\mathrm{Te}$, the 1:1 and 1:2 adducts are associated to one proton in $\left\{\mathrm{H}\left[\mathrm{Re}_{6} \mathrm{Te}_{8}(\mathrm{CN})_{6}\right] \subset(\gamma-\mathrm{CD})_{\times}\right\}^{3-}$ with $\mathrm{x}=1,2$.

\section{Isothermal calorimetric titration}

ITC experiments were carried out to give thermodynamic insights about interactions between the $\gamma$-CD and the $\left[\operatorname{Re}_{6} \mathrm{Q}_{8}(\mathrm{CN})_{6}\right]^{4-}$ clusters as function of the nature of the chalcogenide inner ligand $S$, Se or Te. Selected ITC thermograms and isotherms obtained at $283 \mathrm{~K}$ are shown Figure 6 while full detailed data and related analytical treatments are given in supporting information (SI, §5). ITC results including binding constants, enthalpy $\Delta_{\mathrm{r}} H^{*}$ and entropy $\Delta_{\mathrm{r}} S^{*}$ are given at $298 \mathrm{~K}$ in Table 1. They were analyzed using a two-site binding model involved within a sequential process, except for $\mathrm{S}$ containing cluster for which the second 1:2 step is found negligible. For all the complexes, supramolecular binding is invariably an enthalpically driven process but as the size of the $Q$ ligand increases from $S$ to $T e$, the enthalpy of the complexation tends to decrease gradually. Such a tendency is exactly opposite to that observed by $\mathrm{Nau}$ et al. with dodecaborate $\left[\mathrm{B}_{12} \mathrm{X}_{12}\right]^{2-}$ cluster $(\mathrm{X}=\mathrm{Cl}, \mathrm{Br}$ or I), who reasoned, logically, that such a behavior is in line with increasing dispersion interactions (see Table 1 and Figure 7). ${ }^{[20]}$ Such an apparent discrepancy means that solvation of the rhenium octahedral clusters is mainly governed by the six exposed cyano groups rather that the eight inner $Q$ ligands. In short, increasing the $\sigma$ donor capability of the $Q$ ligands toward the Re centers ongoing from $S$ to $\mathrm{Te}$ weakens the Re-C $\sigma$ overlap which induces the increase of the $\{\mathrm{C}-\mathrm{N}\}$ bond polarization and then the subsequent strengthening of the electrostatic interaction with water molecules of the solvation shell. Such a qualitative explanation was nicely supported by DFT calculations which clearly showed that bonding stabilization comes mainly from $\sigma$ donation between the cyano outer ligands and the $\left\{\operatorname{Re}_{6} \mathrm{Q}_{8}\right\}^{2+}$ core, while corresponding $\mathrm{M}-\mathrm{L}$ bonding energy increases gradually from $Q=S$ to $T e .{ }^{[22]}$ The enthalpic gain appears correlated to entropic penalty according to enthalpy-entropy compensation $\left(R^{2}=0.96\right)$ that usually hold with CDs-based encapsulation process. ${ }^{[23]}$ Actually, thermodynamic profile of the rhenium clusters series resembles that of the perhalogenated 


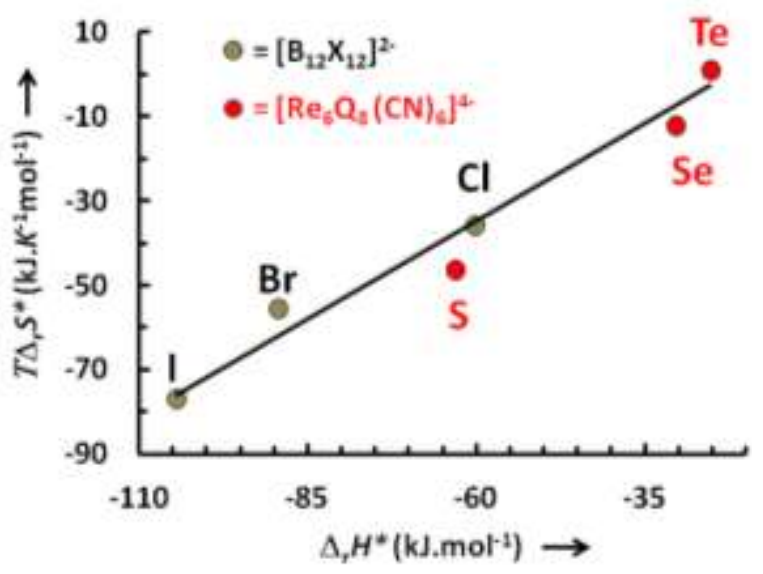

Figure 7. Enthalpy-entropy compensation plot for $1: 1 \gamma$-CD complexes with $\left[\mathrm{Re}_{6} \mathrm{Q}_{8}(\mathrm{CN})_{6}\right]^{4-}$ (red circles) compared with those found for $\left[\mathrm{B}_{12} \mathrm{X}_{12}\right]^{2-}$ dodecaborate anions (grey circles) from Ref. ${ }^{[20]}$.

dodecaborates series ${ }^{[20]}$ and suggests that these ions behave as chaotropic species (water structure breakers). However, as shown in Figure 7, magnitude of the chaotropic character within the $\left[\operatorname{Re}_{6} \mathrm{Q}_{8}(\mathrm{CN})_{6}\right]^{4-}$ series does not increase with the polarizability of the $Q$ ligand, probably due to antagonist influence of the six outer cyano ligands which cancels partially dispersion forces involved within solvation process of the cluster. Nevertheless, the highest affinity was observed with the most bulky anion $\left[\mathrm{Re}_{6} \mathrm{Te}_{8}(\mathrm{CN})_{6}\right]^{4-}$, which optimizes the host-guest dispersion interactions compared to the $\mathrm{S}$ - or Se-containing cluster units.

Table 1. Binding constants $K$ involving rhenium octahedral cluster with $\gamma$-CD and associated thermodynamic parameters (in $\mathrm{kJ} \cdot \mathrm{mol}^{-1}$ ) at $\mathrm{T}=298 \mathrm{~K}$.

\begin{tabular}{lccccc}
\hline$\left[\mathrm{Re}_{6} \mathrm{Q}_{8}(\mathrm{CN})_{6}\right]^{4-}$ & Step & $K\left(\mathrm{M}^{-1}\right)$ & $\Delta_{\mathrm{r}} H^{*}$ & $T_{\mathrm{r}} S^{*}$ & $\Delta_{\mathrm{r}} G^{*}$ \\
\hline $\mathrm{Q}=\mathrm{S}$ & $1: 1$ & 900 & -63.2 & -46.4 & -16.8 \\
& $1: 2$ & - & - & - & - \\
$\mathrm{Q}=\mathrm{Se}$ & $1: 1$ & 1500 & -30.4 & -12.3 & -18.1 \\
& $1: 2$ & 300 & -56.5 & -42.7 & -13.8 \\
$\mathrm{Q}=\mathrm{Te}$ & $1: 1$ & 37700 & -25.3 & +0.8 & -26.1 \\
& $1: 2$ & 12700 & -51.0 & -27.7 & -23.4 \\
\hline
\end{tabular}

Physical-chemical properties of the host-guest
arrangements

\section{Electrochemistry}

As $\left\{\mathrm{Re}_{6} \mathrm{Q}_{8}\right\}^{2+}$ cores are redox active species, influence of $\gamma$-CD upon the electrochemical properties could be examined for the three compounds $(Q=S$, Se or Te). Previous studies reported electrochemical properties of the $\left[\operatorname{Re}_{6} \mathrm{Q}_{8}(\mathrm{CN})_{6}\right]^{4-}$ anions in nonaqueous medium, such as acetonitrile or dichloromethane solvent showing that the 24-electron $\left\{\mathrm{Re}_{6} \mathrm{Q}_{8}\right\}^{2+}$ cores undergo a quasi-reversible one-electron transfer leading to the 23-electron oxidized species. ${ }^{[24]}$ Besides, the oxidizing ability of the $\left\{\mathrm{Re}_{6} \mathrm{Q}_{8}\right\}^{2+}$ core was revealed to be dependent on the $\sigma$ donating character of the $Q$ inner ligands that increases ongoing from $S$ to Te atom. ${ }^{[25]}$ Surprisingly, electrochemical properties of the
Table 2. Main electrochemical potentials (Volt vs. SCE) for chalcogenide clusters 1-3 and their related inclusion compounds in $25 \mathrm{mmol}^{-1} \mathrm{HClO}_{4}$ aqueous solution at $T=298 \mathrm{~K}$.

\begin{tabular}{lllll}
\hline$\left[\mathrm{Re}_{6} \mathrm{Q}_{8}(\mathrm{CN})_{6}\right]^{4-}$ & redox & $\mathrm{E}_{\mathrm{a}}$ & $\mathrm{E}_{\mathrm{c}}$ & $\mathrm{E}_{1 / 2}$ \\
\hline $\mathrm{Q}=\mathrm{S}$ & Free & 0.850 & 0.785 & 0.820 \\
& {$\left[\mathrm{Re}_{6} \cdot \mathrm{CD}\right]^{3-} /\left[\mathrm{Re}_{6} \cdot 2 \mathrm{CD}\right]^{4-}$} & - & - & 0.560 \\
$\mathrm{Q}=\mathrm{Se}$ & Free & 0.615 & 0.545 & 0.580 \\
& {$\left[\mathrm{Re}_{6} \cdot \mathrm{CD}\right]^{3-} /\left[\mathrm{Re}_{6} \cdot \mathrm{CD}\right]^{4-}$} & 0,480 & - & - \\
$\mathrm{Q}=\mathrm{Te}$ & $\mathrm{Free}$ & 0.325 & 0.255 & 0.290 \\
& {$\left[\mathrm{Re}_{6} \cdot \mathrm{CD}\right]^{3-} /\left[\mathrm{Re}_{6} \cdot \mathrm{CD}\right]^{4-}$} & 0.175 & - & - \\
\hline
\end{tabular}

$\left\{\mathrm{Re}_{6} \mathrm{Q}_{8}\right\}^{2+}$ series in aqueous solution have never been reported while many supramolecular processes arise from the remarkable properties of water solvation. Herein, we report for the first time on the electrochemical properties of the $\left[\mathrm{Re}_{6} \mathrm{Q}_{8}(\mathrm{CN})_{6}\right]^{4-}$ anions in aqueous solution and on their deep alteration in the presence of the $\gamma$-CD. Electrochemical study of the native $\mathrm{K}_{4}\left[\mathrm{Re}_{6} \mathrm{Q}_{8}(\mathrm{CN})_{6}\right] \cdot \mathrm{nH}_{2} \mathrm{O}$ compounds has been carried out in 25 mmol. $\mathrm{L}^{-1} \mathrm{HClO}_{4}$ aqueous solution using various amounts of $\gamma-\mathrm{CD}$. The corresponding cyclic voltammograms (CVs) are shown in Figures $8 \mathrm{a}-\mathrm{c}$ and the related data given in Table 2. Each cluster undergoes a monoelectronic wave observed at $E_{1 / 2}=0.820$, 0.580 and $0.290 \mathrm{~V}$ v.s. SCE for $\mathrm{Q}=\mathrm{S}$, Se and Te, respectively. Such a trend appears fully consistent with previous results obtained in $\mathrm{CH}_{3} \mathrm{CN}$ but a $\sim 0.2 \mathrm{~V}$ systematic shift toward positive potential was observed in aqueous medium (see Table 2). Furthermore, variation of the anodic $\left(E_{a}\right)$ and cathodic $\left(E_{c}\right)$ peak currents exhibits a fair linear dependence upon square root of the potential scan rate $\sqrt{S R}$, consistent with a diffusion-controlled electron-transfer kinetic (see SI \$6.1, Figure S11). Influence of $\gamma$ $\mathrm{CD}$ on the electrochemical properties was then investigated showing important changes related to the host-guest structures and solution behavior (see above). Upon gradual addition of $\gamma$ $\mathrm{CD}$, the $\mathrm{CVs}$ of the sulfur-containing cluster $\left[\mathrm{Re}_{6} \mathrm{~S}_{8}(\mathrm{CN})_{6}\right]^{4-}$ retain its reversible shape but undergo a continuous decreasing of its half-wave potential $E_{1 / 2}$ (see Figure 8a) associated to a substantial reduction of the peak currents. Such observations are consistent with i) fast formation / dissociation of the inclusion complexes that maintains equilibrium conditions over the time scale of the experiment and ii) a more slowly diffusing $\gamma-C D$ cluster based species. Furthermore, linear dependence of the anodic and cathodic peak currents upon square root of the potential scan rate $\sqrt{S R}$ is always maintained indicating that $\gamma$ CD complexation does not alter the fast kinetic of the electron transfers (see SI \$6.1, Figure S12). Surprisingly, no attenuation of these variations was observed up to addition of 50 equivalents of $\gamma$-CD indicating that $\gamma$-CD is always involved within the redox reactions according to equation 1 and 2 (see SI $\$ 6.2$, Figure S13). Actually, for large excess of $\gamma$-CD up to 10 equivalents, the speciation diagram established from the stability constant $K_{1: 1}=900 \mathrm{M}^{-1}$ (see Table 1 and SI \$6.3, Figure S14) shows that $1: 1$ host-guest species is prevalent, thus indicating that equation 2 should govern preferentially the redox process.

$$
\begin{aligned}
& \left\{\mathrm{Re}_{6}\right\}_{\mathrm{red}}{ }^{4-}+\mathrm{CD}=\left[\left\{\mathrm{Re}_{6}\right\}_{\mathrm{ox}} \cdot \mathrm{CD}\right]^{3-}+1 \mathrm{e}- \\
& {\left[\left\{\mathrm{Re}_{6}\right\}_{\mathrm{red}} \cdot \mathrm{CD}\right]^{4-}+\mathrm{CD}=\left[\left\{\mathrm{Re}_{6}\right\}_{o x} \cdot 2 \mathrm{CD}\right]^{3-}+1 \mathrm{e}-}
\end{aligned}
$$




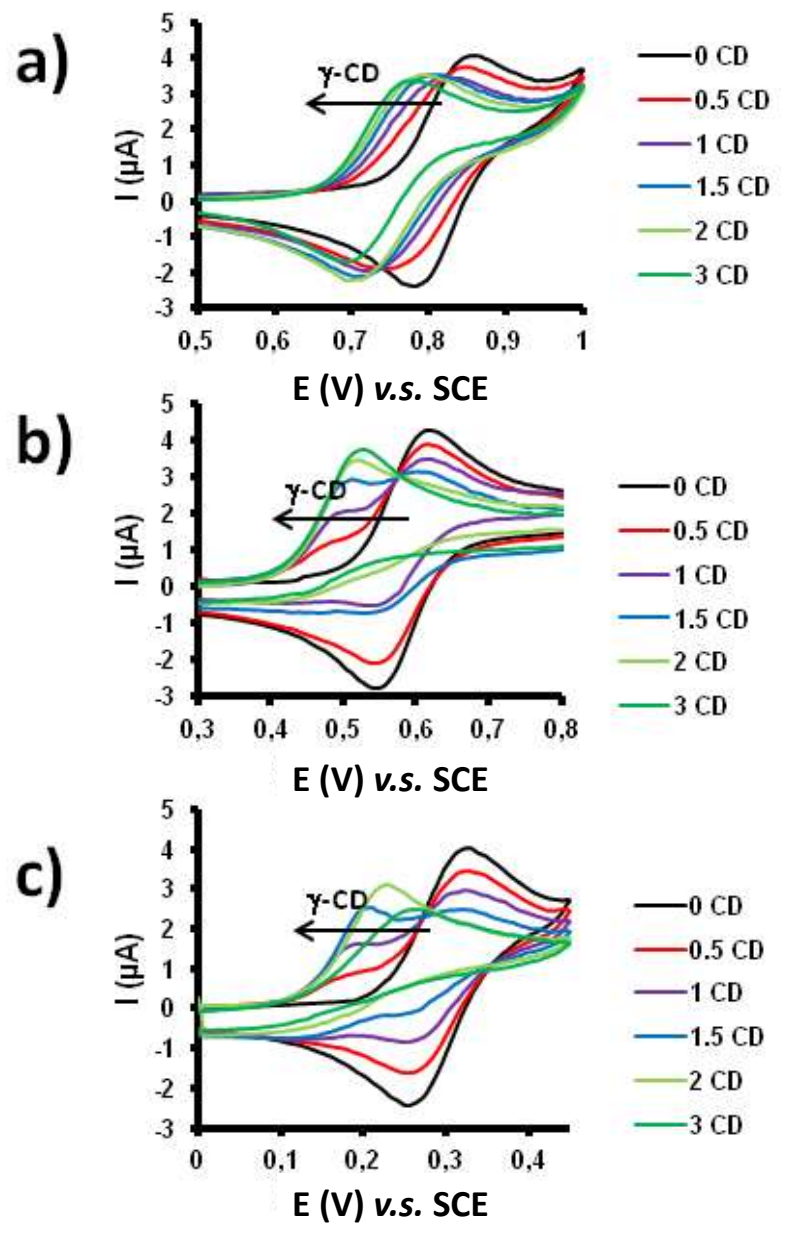

Figure 8. Cyclic voltammetry of the $\left[\operatorname{Re}_{6} \mathrm{Q}_{8}(\mathrm{CN})_{6}\right]^{4-}$ anions with $\mathrm{Q}=\mathrm{S}(\mathrm{a})$, Se (b) or Te (c) $\left(0.5 \mathrm{mmol} . \mathrm{L}^{-1}, 25 \mathrm{mmol} . \mathrm{L}^{-1} \mathrm{HClO}_{4}\right.$ aqueous solution, glassy carbon working electrode, scan rate $50 \mathrm{mV}^{-1} \mathrm{~s}^{-1}$ ) in the presence of increasing amounts of $\gamma$-CD (from 0 to 3 equivalents).

In such a range of composition, a simple relationship between apparent half-wave potential $\mathrm{E}_{1 / 2}^{\mathrm{app}}$ and $p C D$ hold as expressed by equation 3 where $p C D=-\log [C D]$ and $E_{1 / 2}^{C D}$ is the half-wave potential of the redox couple $\left[\left\{\mathrm{Re}_{6}\right\}_{0 x} \cdot 2 \mathrm{CD}\right]^{3-} /\left[\left\{\mathrm{Re}_{6}\right\}_{\mathrm{red}} \cdot \mathrm{CD}\right]^{4-}$ associated to equation (2).

$$
\mathrm{E}_{1 / 2}^{\mathrm{app}}=\mathrm{E}_{1 / 2}^{\mathrm{CD}}+0.059 p \mathrm{CD}
$$

Actually, equation 3 is experimentally justified by a fair linear function $\left(R^{2}=0.996\right)$ giving a slope of $0.0585 \mathrm{~V}$ per $p C D$ unit and $E_{1 / 2}^{C D}=0.560 \mathrm{~V}$ (see SI §6.2, Figure S13). At last, equation 4 is then derived easily from the prevalent redox process (2) where $K_{1: 1}$ corresponds to the stability constant of the 1:1 host-guest reduced species (see Table 1), $\beta_{2}^{\prime}$ is the global formation constant related to equation 5 and $E_{1 / 2}^{0}$ is the half-wave potential of compound 3 in the absence of $\gamma-C D$.

$$
\begin{aligned}
& \mathrm{E}_{1 / 2}^{0}=\mathrm{E}_{1 / 2}^{\mathrm{CD}}+0.059 \log \frac{\beta_{2}^{\prime}}{\mathrm{K}_{11}} \\
& \left\{\mathrm{Re}_{6}\right\}_{\mathrm{ox}}{ }^{3-}+2 \mathrm{CD}=\left[\left\{\mathrm{Re}_{6}\right\}_{\mathrm{ox}} \cdot 2 \mathrm{CD}\right]^{3-}
\end{aligned}
$$

$0.820 \mathrm{~V}$ and $K_{11}=900 \mathrm{M}^{-1}$, equation 4 leads to $\beta_{2}^{\prime}=2.210^{7} \mathrm{M}^{-2}$. This result highlights the high affinity of the oxidized species $\left[\mathrm{Re}_{6} \mathrm{~S}_{8}(\mathrm{CN})_{6}\right]^{3-}$ for $\gamma$-CD while such a global constant $\beta_{2}$ was found negligible for a similar process involving the reduced cluster $\left[\operatorname{Re}_{6} \mathrm{~S}_{8}(\mathrm{CN})_{6}\right]^{4-}$ (see Table 1). It should be worth noting that for $\gamma$-CD equivalent number below 10, analytical treatment remains quite tricky mainly due to i) the presence of different species resulting from the combinations of the redox and hostguest states and ii) the variation of the $\gamma$-CD concentration in the diffusion layer as function of applied potential.

Strikingly, the Se- and Te-containing clusters (compounds 2 and 1) behave differently from that previously observed with the sulfur derivative. Thus, gradual addition of $\gamma$-CD affects significantly the CVs of the compounds 1 and 2 (shown in Figures $8 \mathrm{~b}-\mathrm{c}$ ), by the disappearance of the initial redox waves of the solvated cluster for the benefit of a new anodic potential peak systematically shifted toward lower potential at about 0.480 $\mathrm{V}$ and $0.175 \mathrm{~V}$ for $\mathrm{Q}=\mathrm{Se}$ and $\mathrm{Q}=\mathrm{Te}$, respectively. Besides, as the $\gamma$-CD concentration increases, these new anodic peaks slowly move toward more positive potential values (see Figures $8 b-c)$. Furthermore, while the shape of the oxidation peaks remains almost unchanged in the presence of $\gamma$-CD, the reverse reduction wave appears totally cancelled for both Se- and Tecontaining clusters. Then, as the global redox process appear fully irreversible, the anodic peak currents exhibit a fair linear dependence upon square root of the potential scan rate (see SI $\S 7.1$, Figure S12), indicating that the oxidation process remains fast while the reverse reduction becomes extremely slow in the presence of $\gamma$-CD. Thus, such a redox behavior appears rather consistent with slow formation / dissociation of the host-guest complexes on the time scale experiment. Thus, in the presence of 0.5 equivalent of $\gamma-C D$, the new anodic peak should correspond to redox process involving the prevalent frozen 1:1 host guest species (see equation 6).

$$
\left[\left\{\mathrm{Re}_{6}\right\}_{\mathrm{red}} \cdot \mathrm{CD}\right]^{4-}=\left[\left\{\mathrm{Re}_{6}\right\}_{\mathrm{ox}} \cdot \mathrm{CD}\right]^{3-}+1 \mathrm{e}-
$$

Assuming that Nernst equation pertains, the stability constant of the 1:1 host-guest oxidized species can be estimated from equation 7 where $E_{a}^{0}$ and $E_{a}^{C D}$ are the anodic peak potential in the absence and in the presence of $\gamma-C D$, respectively and $K_{11}^{\prime}$ the stability constant of the oxidized 1:1 host-guest complex.

$$
\mathrm{E}_{\mathrm{a}}^{0}=\mathrm{E}_{\mathrm{a}}^{\mathrm{CD}}+0.059 \log \frac{\mathrm{K}_{11}^{\prime}}{\mathrm{K}_{11}}
$$

Using experimental values given in Table 1 and $2, K_{11}^{\prime}$ values have been determined from equation 7 , giving $K_{11}^{\prime}=2.4 \cdot 10^{5} \mathrm{M}^{-1}$ and $K_{11}^{\prime}=1.0 \cdot 10^{7} \mathrm{M}^{-1}$ for oxidized $1: 1$ inclusion complexes based on $\left[\mathrm{Re}_{6} \mathrm{Se}_{8}(\mathrm{CN})_{6}\right]^{3-}$ and $\left[\mathrm{Re}_{6} \mathrm{Te}_{8}(\mathrm{CN})_{6}\right]^{3-}$ clusters, respectively. Then at larger values of $\gamma$-CD equivalent number, the anodic peak potential shifts slowly toward positive values to reach limiting values. In this range of composition, speciation curves established from ITC experiments indicate gradual changes of the host-guest composition from 1:1 to $1: 2$ stoichiometry, thus in such conditions, this limiting anodic peak potential should be close to that of the $1: 2$ redox couple $\left[\left\{\mathrm{Re}_{6}\right\} \cdot 2 \mathrm{CD}\right]^{3-}$, $\left[\left\{\mathrm{Re}_{6}\right\} \cdot 2 \mathrm{CD}\right]^{4-}$. Nevertheless, due to the irreversible character of the redox processes supported by the flattening of the anodic peaks observed for large $\gamma$-CD equivalents, any straight quantitative analysis remains quite difficult and requires further 


\section{FULL PAPER}

investigations with regard to the oxidized forms behavior in the presence of the cyclodextrins. However, these preliminary results highlight important electrochemical features that are strongly related to the nature of the inner $Q$ ligands in octahedral cyano clusters $\left[\operatorname{Re}_{6} \mathrm{Q}_{8}(\mathrm{CN})_{6}\right]^{4-/ 3-}$. Importantly, this study reveals that the sulfur-containing cluster leading to the less stable hostguest arrangement behaves as highly dynamic redox host-guest system while features of the other two clusters that exhibit higher host-guest stability are consistent with a frozen redox behavior. Besides, it should be worth mentioning that such a frozen behavior has been previously evidenced by ${ }^{1} \mathrm{H}$ and ${ }^{125} \mathrm{Te}$ NMR for the reduced host-guest complex based on the Tecontaining cluster (see Figure 5a). Furthermore, for the three cluster units $(Q=S$, Se and Te), complexation by $\gamma-C D$ leads in all cases to the decrease of the half-wave potential, meaning clearly that host-guest affinity of the oxidized species $\left[\operatorname{Re}_{6} \mathrm{Q}_{8}(\mathrm{CN})_{6}\right]^{3-}$ is significantly greater than that of the reduced one $\left[\operatorname{Re}_{6} \mathrm{Q}_{8}(\mathrm{CN})_{6}\right]^{4-}$. Such a trend is nicely supported by quantitative analysis of the electrochemical data summarized in Table 2. Although the full understanding of this observation should require further investigations, especially about the thermodynamic contributors of the solvated oxidized derivatives, reducing of the ionic charge from 4 - to 3 - should have as main consequence the destabilization of the solvation shell by decreasing ion-dipole interactions. Similar observations were made previously with the ferrocene/ferrocenium as redox active guest interacting with $\beta-C D$ as host. ${ }^{[24]}$ Lowering the ionic charge of the guest would make easier the cluster transfer from a solvated to an embedded situation. In other word, the driving force of the encapsulation process should be mainly governed by effective water structure recovery, a process highly orchestrated by the chaotropic nature of the octahedral clusters.

\section{Luminescence properties}

The UV-vis spectra of aqueous solutions of $\left[\operatorname{Re}_{6} \mathrm{~S}_{8}(\mathrm{CN})_{6}\right]^{4-}$ and $\left[\mathrm{Re}_{6} \mathrm{Se}_{8}(\mathrm{CN})_{6}\right]^{4-}$ are nearly unchanged in the presence of $\gamma$-CD. The supramolecular interaction between $\left[\mathrm{Re}_{6} \mathrm{Te}_{8}(\mathrm{CN})_{6}\right]^{4-}$ ion and $\gamma-C D$ is manifested by only a small red shift of the $\left[\operatorname{Re}_{6} \mathrm{Te}_{8}(\mathrm{CN})_{6}\right]^{4-}$ absorption band from $416 \mathrm{~nm}$ to $420 \mathrm{~nm}$ (see $\S 8.1$ Figure S15).

$\left[\mathrm{Re}_{6} \mathrm{Q}_{8}(\mathrm{CN})_{6}\right]^{4-}$ clusters and their inclusion complexes with $\gamma-\mathrm{CD}$ exhibit luminescence emission spectra in the red/NIR region with almost the same maxima, indicating that the nature of the cluster triplet states is not affected by interaction with $\gamma$-CD (see SI §7.2, Figure S16). In all cases, luminescence quantum yields and corresponding lifetimes (i.e., triplet state lifetimes) of inclusion complexes increase when compared with free (unbound) clusters in aqueous solutions. The changes are minor for $\left[\operatorname{Re}_{6} \mathrm{~S}_{8}(\mathrm{CN})_{6}\right]^{4-}$, reflecting the weak effects of $\gamma$-CD on the cluster as described above (see SI §7.2, Figure S17). In contrast, the formation of inclusion complexes with $\left[\mathrm{Re}_{6} \mathrm{Se}_{8}(\mathrm{CN})_{6}\right]^{4-}$ and $\left[\mathrm{Re}_{6} \mathrm{Te}_{8}(\mathrm{CN})_{6}\right]^{4-}$ clusters enhances luminescence intensities as characterized by increasing luminescence quantum yields and extension of lifetimes (Table 3, see SI §7.2, Figures S16, S17). In the presence of $\gamma-C D$, the luminescence decay profile of $\left[\mathrm{Re}_{6} \mathrm{Se}_{8}(\mathrm{CN})_{6}\right]^{4-}$ becomes biphasic with the increasing contribution of a long-lived component at higher $\gamma$ $\mathrm{CD} /\left[\mathrm{Re}_{6} \mathrm{Se}_{8}(\mathrm{CN})_{6}\right]^{4-}$ molar ratios (Figure 9B). This behavior may be interpreted by the contribution of at least two species with

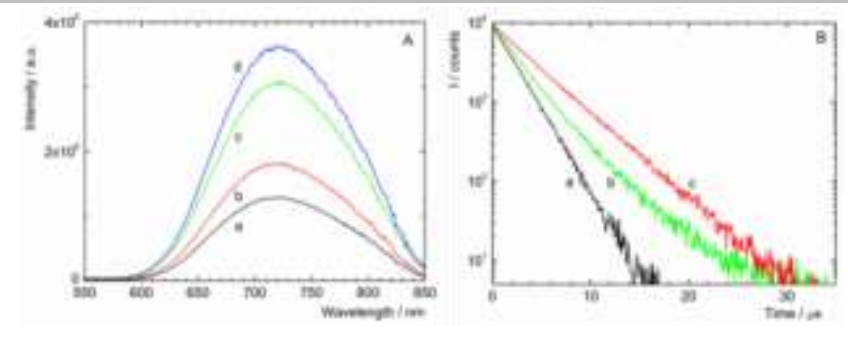

Figure 9. Luminescence properties of $8 \cdot 10^{-5} \mathrm{~mol}^{-\mathrm{L}^{-1}}\left[\mathrm{Re}_{6} \mathrm{Se}_{8}(\mathrm{CN})_{6}\right]^{4-}$ aqueous solutions in the presence of $\gamma-C D$ in water. A) Luminescence emission spectra in a) air-saturated water, b) oxygen-free water in the absence and in the presence of c) 2.8 or d) $5.4 \mathrm{mM} \gamma$-CD. B) Luminescence decay curves a) in oxygen-free water and in the presence of b) 1.0 or c) $5.4 \mathrm{mM} \gamma$-CD.

different luminescence lifetimes in the equilibrium, i.e., solvated $\left[\mathrm{Re}_{6} \mathrm{Se}_{8}(\mathrm{CN})_{6}\right]^{4-}$ species and corresponding inclusion complexes with $\gamma$-CD. Evidently, the $1: 1$ and $1: 2$ complexes are not spectroscopically distinguishable and have the same or very similar luminescence parameters. Nevertheless, introducing a large excess of $\gamma$-CD in the cluster solution leads to the recovery of the mono exponential behavior of the emission decay profile, consistent with predominant formation of the 1:2 complex.

The increase of luminescence parameters upon inclusion of the clusters to $\gamma$-CD can be attributed to the combination of two factors: exclusion of water molecules from the solvation shell of cluster molecules in the cyclodextrin cavity and reduction of collisional quenching by water molecules from the bulk. ${ }^{[27]}$ As shown recently by analyzing the magnitude of $\mathrm{D}_{2} \mathrm{O} / \mathrm{H}_{2} \mathrm{O}$ isotopic effects on the triplet state behavior of these clusters, ${ }^{[28]}$ energy transfer from their excited states to $\mathrm{H}_{2} \mathrm{O}$ vibrational modes leads to extensive non-radiative deactivation. Indeed, due to hydrophobic character inside the cyclodextrin cavity and the fact that water molecules are expelled from the interior and substituted with the cluster body, contacts of excited cluster molecules with water molecules are reduced.

Table 3. Luminescence properties of $\left[\operatorname{Re}_{6} \mathrm{Q}_{8}(\mathrm{CN})_{6}\right]^{4-}$ clusters in water at room temperature: $\Phi_{L}$ is the luminescence quantum yield, $\Phi_{\llcorner}(C D)$ is the luminescence quantum yield in the presence of $\gamma \mathrm{CD}(>5 \mathrm{mM}$, measured for excitation wavelengths varying from 340 to $420 \mathrm{~nm}$ ), $\mathrm{T}_{0}$ and $\mathrm{T}_{\mathrm{air}}$ are the lifetimes of the triplet states, $T_{0}(C D)$ and $T_{\text {air }}(C D)$ are the lifetimes of the triplet states of bound clusters with $\gamma$-CD $(>20 \mathrm{mM})$.

\begin{tabular}{ccccccc}
\hline $\mathrm{Q}$ & $\Phi_{L^{[\mathrm{d}]}}$ & $\Phi_{\mathrm{L}}(\mathrm{CD})^{[\mathrm{d}]}$ & $\mathrm{T}_{0} / \mu \mathrm{S}^{[\mathrm{d}]}$ & $\mathrm{T}_{\mathrm{air}} / \mu \mathrm{S}^{[\mathrm{e}]}$ & $\mathrm{T}_{0}(\mathrm{CD}) / \mu \mathrm{S}^{[\mathrm{d}]}$ & $\mathrm{T}_{\mathrm{air}}(\mathrm{CD}) / \mu \mathrm{S}^{[\mathrm{e}]}$ \\
$\mathrm{S}$ & $0.009^{[\mathrm{a}]}$ & $<0.01$ & $1.17^{[\mathrm{b}]}$ & $1.06^{[\mathrm{b}]}$ & $1.27^{[\mathrm{b}]}$ & $1.15^{[\mathrm{b}]}$ \\
$\mathrm{Se}$ & $0.015^{[\mathrm{a}]}$ & 0.03 & $2.12^{[\mathrm{b}]}$ & $1.50^{[\mathrm{b}]}$ & $4.25^{[\mathrm{b}]}$ & $2.53^{[\mathrm{b}]}$ \\
$\mathrm{Te}$ & $0.004^{[\mathrm{a}]}$ & 0.01 & $0.43^{[\mathrm{c}]}$ & $0.34^{[\mathrm{c}]}$ & $0.75^{[\mathrm{c}]}$ & $0.69^{[\mathrm{c}]}$ \\
\hline
\end{tabular}

[a] data from ref. ${ }^{[26]}$. ${ }^{[b]}$ Recorded at $720 \mathrm{~nm} .{ }^{[c]}$ Recorded at $\left.740 \mathrm{~nm} .{ }^{[\mathrm{d}]}\right] \mathrm{n}$ oxygen free water. ${ }^{[e]}$ In air-saturated water.

In order to represent accurately how the inclusion of the clusters into the $\gamma$-CD cavity affects the efficiency of oxygen quenching of the triplet states, we used the relationship $1-\left(\mathrm{T}_{\text {air }} / \mathrm{T}_{0}\right)$ to yield the fraction of the triplet states quenched by oxygen under airsaturated conditions (see Table 3). In agreement with negligible effects of $\gamma$-CD on the properties of $\left[\operatorname{Re}_{6} \mathrm{~S}_{8}(\mathrm{CN})_{6}\right]^{4-}$, the cluster triplet states of inclusion complex are minimally affected by oxygen with a low fraction of $9 \%$, which is the same as for free 
$\left[\operatorname{Re}_{6} \mathrm{~S}_{8}(\mathrm{CN})_{6}\right]^{4-}$. On the other side, the fraction increases from 29 to $40 \%$ in the case of $\left[\mathrm{Re}_{6} \mathrm{Se}_{8}(\mathrm{CN})_{6}\right]^{4-}$ inclusion complexes, whereas it decreases from 21 to only $8 \%$ for $\left[\operatorname{Re}_{6} T_{8}(C N)_{6}\right]^{4-}$ complexes with $\gamma$-CD. These effects reflect nicely the fact that while the formation of inclusion complexes increases the lifetimes of the triplet states, thus promoting higher fractions of their quenching by oxygen, it is also accompanied with the drop of diffusion coefficients (see previous paragraph), leading to less effective collisional quenching of the triplet states with oxygen. In the case of $\left[\mathrm{Re}_{6} \mathrm{Se}_{8}(\mathrm{CN})_{6}\right]^{4-}$, the increase of the lifetime overcomes the effect of slower diffusion of the inclusion complex. For $\left[\operatorname{Re}_{6} \mathrm{Te}_{8}(\mathrm{CN})_{6}\right]^{4-}$ complexes with $\gamma$-CD, the increase of the lifetime is limited due to deactivation of the excited states through internal conversion and cannot compensate for slower diffusion, resulting in a small fraction of the triplet states quenched by oxygen.

\section{Conclusions}

The self-assembly between native $\gamma$-CD and octahedral $\left[\mathrm{Re}_{6} \mathrm{Q}_{8}(\mathrm{CN})_{6}\right]^{4-}$ clusters (with $\mathrm{Q}=\mathrm{S}$, Se and $\mathrm{Te}$ ) has been observed and studied both in solid state and in aqueous solution Varying systematically the inner face-capping chalcogenide ligands of these clusters allowed evidencing key parameters required for the molecular recognition efficiency. In addition to size-fitness, preorganization or attractive host-guest interactions, the chaotropic nature of these clusters should probably have a decisive contribution to the supramolecular association involving water-soluble host and guest species. For instance, the smallest cluster which contains sulfur as inner ligand interacts preferentially with the primary faces of the $\gamma$-CD to give a $1: 2$ supramolecular assembly while the bulkier $\left[\operatorname{Re}_{6} \mathrm{Se}_{8}(\mathrm{CN})_{6}\right]^{4-}$ and $\left[\operatorname{Re}_{6} \mathrm{Te}_{8}(\mathrm{CN})_{6}\right]^{4-}$ ions appear closely embedded through the secondary faces of the host. Such structural features observed in the solid state from X-ray diffraction analysis are nicely correlated to solution studies which reveals the host-guest stability increases significantly in the following order $\mathrm{S}<\mathrm{Se}<\mathrm{Te}$ Interestingly, supramolecular interactions provoke significant alterations of the intrinsic physical-chemical properties of the $\left[\operatorname{Re}_{6} \mathrm{Q}_{8}(\mathrm{CN})_{6}\right]^{4-}$ clusters such as redox tuning or luminescence enhancement in aqueous solution. Then, the formation of highly stable supramolecular assemblies using functional octahedral clusters (redox and luminescent active) CDs opens a promising way to design advanced multifunctional materials, relevant for photocatalysis or biomedical applications.

\section{Experimental Section}

Materials and Methods. All reagents were purchased from commercial sources and used without further purification. $A_{4}\left[R_{6} X_{8}(C N)_{6}\right](A=K, N a$; $\mathrm{X}=\mathrm{S}, \mathrm{Se}, \mathrm{Te})$ were synthesized as described in literature. ${ }^{[17 \mathrm{~b}, 29]}$

Fourier Transformed Infrared (FT-IR) spectra were recorded on a Vertex 80 spectrometer. Elemental analyses $(\mathrm{C}, \mathrm{H}, \mathrm{N}, \mathrm{S})$ were carried on an Euro EA 3000 instrument. Energy-dispersive X-ray spectroscopy (EDX) measurements were performed using a SEM-FEG (Scanning Electron Microscope enhanced by a Field Emission Gun) equipment (JSM 7001-F Jeol). The measures were acquired with a SDD XMax $50 \mathrm{~mm}^{2}$ detector and the Aztec (Oxford) system working at $15 \mathrm{kV}$ and $10 \mathrm{~mm}$ working distance. The quantification is realized with the standard library provided by the constructor using La lines. Water and cyclodextrin contents were determined by thermal gravimetric (TGA) analysis with a Mettler Toledo TGA/DSC 1, STAR ${ }^{\text {e }}$ System apparatus or with a NETZSCH TG 209 F1 device under oxygen flow $\left(50 \mathrm{~mL} \mathrm{~min}^{-1}\right)$ at a heating rate of $5^{\circ} \mathrm{C} \mathrm{min} \mathrm{m}^{-1}$ up to $700^{\circ} \mathrm{C}$. NMR studies: All NMR spectra were measured on a Bruker Avance 400 spectrometer in $\mathrm{D}_{2} \mathrm{O}$ at $300 \mathrm{~K} .{ }^{1} \mathrm{H}$ and ${ }^{13} \mathrm{C}$ NMR spectra were recorded at 400.1 and $100.6 \mathrm{MHz}$ respectively, referenced to the TMS signal. ${ }^{77} \mathrm{Se}$ and ${ }^{125} \mathrm{Te} \mathrm{NMR}$ spectra were measured at Larmor frequencies of 76.3 and $126.3 \mathrm{MHz}$, using $\mathrm{H}_{2} \mathrm{SeO}_{3}$ in alkaline solution (1272.6 ppm) and aqueous $\mathrm{H}_{6} \mathrm{TeO}_{6}(713 \mathrm{ppm})$ as external secondary references, respectively. Translational diffusion measurements were performed using Bruker's "ledbpgs2s" stimulated echo DOSY pulse sequence including bipolar and spoil gradients. Apparent diffusion coefficients were obtained using an adapted algorithm based on the inverse Laplace transform stabilized by maximum entropy. ${ }^{[30]}$ Electrospray Ionization Mass Spectrometry: Electrospray ionization (ESI) mass spectra were collected using a Q-TOF instrument supplied by WATERS. Samples were solubilized in water at a concentration of $10^{-4} \mathrm{M}$ and were introduced into the MS via an ACQUITY UPLC WATERS system whilst a Leucine Enkephalin solution was co-injected via a micro pump as internal standard. Isothermal Titration Calorimetry (ITC): Formation constants and inclusion enthalpies were simultaneously determined for each $\gamma-\mathrm{CD} /\left[\operatorname{Re}_{6} \mathrm{Q}_{8}(\mathrm{CN})_{6}\right]^{4-}$ systems by the use of an isothermal calorimeter ( ITC $_{200}$, MicroCal Inc., USA). See supplementary information for further details.

Electrochemistry. Purified water was used throughout. It was obtained by passing water through a RiOs 8 unit followed by a Millipore-Q Academic purification set. All reagents were of high-purity grade and were used as purchased without further purification. Cyclic voltammetric (CV) experiments were carried out with an Methrohm Autolab PGSTAT12 potentiostat/galvanostat associated with a GPES electrochemical analysis system (EcoChemie). Measurements were performed at room temperature in a conventional single compartment cell. A glassy carbon (GC) electrode with a diameter of $3 \mathrm{~mm}$ was used as the working electrode. The auxiliary electrode was a Pt plate placed within a fritted-glass isolation chamber and potentials are quoted against a saturated calomel electrode (SCE). The solutions were deaerated thoroughly for at least 30 minutes with pure argon and kept under a positive pressure of this gas during the experiments.

Single-crystal X-ray diffraction analysis. The crystal structures of compound $\mathbf{1}$ and $\mathbf{2}$ were determined by X-ray analysis on an Xcalibur (Agilent Technologies) single crystals diffractometer, at $130 \mathrm{~K}$, using graphite-monochromated Mo $(\lambda=0.71073 \AA)$ radiation. The reflections intensities were measured $\varphi$-scanning of narrow $\left(0.5^{\circ}\right)$ frames. Intensity data collection of compound 3 was carried out at $T=200(2) \mathrm{K}$ with a Bruker D8 VENTURE diffractometer equipped with a PHOTON 100 CMOS bidimensional detector using a high brilliance $I \mu S$ microfocus $X$ ray Mo $\mathrm{Ka}$ monochromatized radiation $(\lambda=0.71073 \AA)$. Empirical absorption correction was applied with SCALE3 ABSPACK program ${ }^{[31]}$ or using the SADABS program. ${ }^{[32]}$ The structure was solved by direct method and refined with full-matrix least-squares treatment, anisotropically for non-hydrogen atoms in SHELXL ${ }^{[33]}$ using OLEX2. [34] Crystals were glued in paratone to prevent any loss of crystallization water. The remaining non-hydrogen atoms were located from Fourier differences and were refined with anisotropic thermal parameters. Positions of the hydrogen atoms belonging to the $\gamma$-cyclodextrins were calculated and refined isotropically using the gliding mode. Crystallographic data for 1: Tetragonal, 1422, $a=b=23.8046(2), c=$ 57.1588(7) $\AA, \alpha=\beta=\gamma=90^{\circ}, V=32389.5(7) \AA^{3}, R_{1}=0.0479, w R_{2}=0.1460$, GOF $=1.100$ for 15244 independent reflections with $I>2 s(I)$. Crystallographic data for 2: Tetragonal, 1422, $a=b=23.8608(2), c=$ 57.4481(9) $\AA, \alpha=\beta=\gamma=90^{\circ}, V=32707.4(8) \AA^{3}, R_{1}=0.0534, w R_{2}=0.1622$, $\mathrm{GOF}=1.146$ for 14796 independent reflections with $\mathrm{I}>2 \mathrm{~s}(\mathrm{I})$. Crystallographic data for 3: Monoclinic, $C 2, a=63.823(4), b=17.8218(11)$, $C=17.7578(11) \AA, \alpha=\gamma=90^{\circ}$ and $\beta=104.248(2)^{\circ}, V=19577(2) \AA^{3}, R_{1}=$ $0.0545, \mathrm{wR}_{2}=0.1267, \mathrm{GOF}=1.034$ for 47105 independent reflections 


\section{FULL PAPER}

with $\mathrm{I}>2 \mathrm{~s}(\mathrm{I})$. For the compounds $\mathbf{1}$ and $\mathbf{3}$, disorder is observed on the encapsulated clusters. In the compound $\mathbf{1}$, two positions are observed for $\left[\mathrm{Re}_{6} \mathrm{Te}_{8}(\mathrm{CN})_{6}\right]^{4-}$ (occupancy of site $1=94 \%$ and occupancy of site $2=$ $6 \%$ ). In this case it was not possible to locate the cyano group of the cluster with occupancy of $6 \%$. In the compound 3 , the encapsulated cluster $\left[\operatorname{Re}_{6} \mathrm{~S}_{8}(\mathrm{CN})_{6}\right]^{4-}$ is three fold disordered on three positions (occupancy of site $1=90 \%$, occupancy of site $2=5 \%$, occupancy of site $3=5 \%)$. In this, the $\left[\operatorname{Re}_{6} \mathrm{~S}_{8}(\mathrm{CN})_{6}\right]^{4-}$ of site 1 is well defined. For the sites 2 and 3 , only the $\left\{R_{6}\right\}$ cores have been located. Selected Crystallographic data for single-crystal X-ray diffraction studies are summarized in Table S1. CCDC-1813565, CCDC-1813564 and CCDC1813563 for compounds $\mathbf{1}, \mathbf{2}$ and $\mathbf{3}$, respectively, also contain the supplementary crystallographic data. These data can be obtained free of charge via www.ccdc.cam.ac.uk/data request/cif.

Optical measurements. UV-vis absorption spectra of solutions were recorded on a Perkin Elmer Lambda 35 spectrometer. Luminescence properties were monitored on a Fluorolog 3 spectrometer equipped with a cooled TBX-05-C photon detection module (Horiba Jobin Yvon). The same instrument was used for luminescence lifetime experiments using an excitation at $390 \mathrm{~nm}$ (SpectraLED-390, Horiba Scientific). The decay curves were fitted to exponential functions by the iterative reconvolution procedure of the DAS6 software (v. 6.8, Horiba Jobin Yvon). Absolute photoluminescence quantum yields were measured using a Quantaurus QY C11347-1 spectrometer (Hamamatsu). 8.10-5 mol.L-1 Cluster aqueous solutions were investigated using excitation wavelengths between 340 and $420 \mathrm{~nm}$. For all measurements, oxygen was removed by saturating the solutions with a continuous flow of argon.

Synthesis of $\mathrm{Na}_{4}\left\{\left[\mathrm{Re}_{6} \mathrm{Te}_{8}(\mathrm{CN})_{6}\right] \subset(\gamma-\mathrm{CD})_{2}\right\} \cdot(\gamma-\mathrm{CD}) \cdot 3 \mathrm{H}_{2} \mathrm{O}$ (1). $0.1 \mathrm{~g}$ $(0.042 \mathrm{mmol})$ of $\mathrm{Na}_{4}\left[\mathrm{Re}_{6} \mathrm{Te}_{8}(\mathrm{CN})_{6}\right]$ was dissolved in $10 \mathrm{~mL}$ of distilled water, after that $0.163 \mathrm{~g}(0.126 \mathrm{mmol})$ of $\gamma$-CD was added under stirring and gentle heating at $50{ }^{\circ} \mathrm{C}$. Final solution was allowed to slowly evaporate which gave orange cubic crystals of $\mathrm{Na}_{4}\left\{\left[\mathrm{Re}_{6} \mathrm{Te}_{8}(\mathrm{CN})_{6}\right] \subset[\gamma\right.$ $\left.\mathrm{CD}]_{2}\right\} \cdot(\gamma-\mathrm{CD}) \cdot 30 \mathrm{H}_{2} \mathrm{O}$. Yield $0.245 \mathrm{~g}(86 \%)$ of pure crystalline product. Anal. Calcd for $\mathrm{C}_{150} \mathrm{H}_{300} \mathrm{~N}_{6} \mathrm{Na}_{4} \mathrm{O}_{150} \mathrm{Re}_{6} \mathrm{Te}_{8}$ : C, 26.42; $\mathrm{H}, 4.44 ; \mathrm{N}, 1.23$. Found: C, 26.5; $\mathrm{H}, 4.2 ; \mathrm{N}, 1.3 . \mathrm{IR}\left(\mathrm{KBr}, \mathrm{cm}^{-1}\right): \mathrm{v}=3406(\mathrm{~s}), 2926(\mathrm{~m})$, 2088 (s), 1639 (s), 1416 (w), 1371 (w), 1337 (w), 1303 (w), 1242 (w), $1157(\mathrm{~m}), 1105(\mathrm{w}), 1078(\mathrm{w}), 1024(\mathrm{~s}), 999(\mathrm{w}), 941(\mathrm{w}), 850(\mathrm{w}), 760$ (w), 707 (w), 581 (w), 528 (w), 405 (w). EDS shows Re : Te : Na ratio = $6: 7.8: 3.9$. Thermogravimetric analysis revealed a weight loss of about $8 \%$ from 50 to $200^{\circ} \mathrm{C}$ (the theoretical weight loss of $30 \mathrm{H}_{2} \mathrm{O}$ is $7.93 \%$ ).

$\mathrm{K}_{4}\left\{\left[\mathrm{Re}_{6} \mathrm{Se}_{8}(\mathrm{CN})_{6}\right] \subset(\gamma-\mathrm{CD})_{2}\right\} \cdot(\gamma-\mathrm{CD}) \cdot 40 \mathrm{H}_{2} \mathrm{O}$ (2). $0.082 \mathrm{~g}(0.042 \mathrm{mmol})$ of $\mathrm{K}_{4}\left[\mathrm{Re}_{6} \mathrm{Se}_{8}(\mathrm{CN})_{6}\right]$ was dissolved in $10 \mathrm{~mL}$ of distilled water, after that $0.163 \mathrm{~g}(0.126 \mathrm{mmol})$ of $\gamma-\mathrm{CD}$ was added under stirring and gentle heating at $50{ }^{\circ} \mathrm{C}$. Final solution was allowed to slowly evaporate which gave orange cubic crystals of $\mathrm{K}_{4}\left\{\left[\operatorname{Re}_{6} \mathrm{Te}_{8}(\mathrm{CN})_{6}\right] \subset(\gamma-\mathrm{CD})_{2}\right\} \cdot(\gamma-\mathrm{CD}) \cdot 40 \mathrm{H}_{2} \mathrm{O}$. Yield $0.229 \mathrm{~g}(82 \%)$ of pure crystalline product. Anal. Calcd for $\mathrm{C}_{150} \mathrm{H}_{290} \mathrm{~N}_{6} \mathrm{~K}_{4} \mathrm{O}_{145} \mathrm{Re}_{6} \mathrm{Se}_{8}: \mathrm{C}, 28.14 ; \mathrm{H}, 4.56 ; \mathrm{N}, 1.31$. Found: $\mathrm{C}, 28.2 ; \mathrm{H}$, 4.4; N, 1.4. IR (KBr, cm $\left.{ }^{-1}\right): v=3417(\mathrm{~s}), 2926(\mathrm{~m}), 2112(\mathrm{~s}), 1636(\mathrm{w})$, $1413(w), 1369(w), 1340(w), 1305(w), 1244(w), 1201(w), 1159(m)$, $1103(w), 1078(w), 1024(s), 997(w), 941(w), 856(w), 760(w), 708(w)$, $580(w), 530$ (w). EDS shows Re : Se : K ratio $=6: 8.2: 3.9$. Thermogravimetric analysis revealed a weight loss of about $7 \%$ from 50 to $200{ }^{\circ} \mathrm{C}$ (the theoretical weight loss of $40 \mathrm{H}_{2} \mathrm{O}$ is $7.3 \%$ ).

$\mathrm{Cs}_{4} \mathrm{~K}_{8}\left\{\left[\mathrm{Re}_{6} \mathrm{~S}_{8}(\mathrm{CN})_{6}\right] \subset(\gamma-\mathrm{CD})_{2}\right\} \cdot 2\left[\operatorname{Re}_{6} \mathrm{~S}_{8}(\mathrm{CN})_{6}\right] \cdot \mathbf{2}(\gamma-\mathrm{CD}) \cdot 49 \mathrm{H}_{2} \mathrm{O}$ (3). $0.1 \mathrm{~g}$ $(0.059 \mathrm{mmol})$ of $\mathrm{K}_{4}\left[\mathrm{Re}_{6} \mathrm{~S}_{8}(\mathrm{CN})_{6}\right]$ was dissolved in $1 \mathrm{~mL}$ of water, after that $0.25 \mathrm{~g}(0.178 \mathrm{mmol})$ of $\gamma-\mathrm{CD}$ was dissolved in $1 \mathrm{~mL}$ of water and added to cluster solution. After that $0.05 \mathrm{~g}(0.297 \mathrm{mmol})$ of $\mathrm{CsCl}$ was added to the solution. Then ethanol vapor was allowed to diffuse: a $10 \mathrm{~mL}$ vessel containing $2 \mathrm{~mL}$ of the final solution of the complex in water was placed into a $250 \mathrm{~mL}$ vessel with a tight-fitting lid containing $50 \mathrm{~mL}$ of ethanol. The crystals obtained after two days were collected, washed with mixture water/ethanol and dried on air. Yield: $0.15 \mathrm{~g}(66 \%)$. Anal. Calcd for $\mathrm{C}_{210} \mathrm{H}_{418} \mathrm{Cs}_{4} \mathrm{~K}_{8} \mathrm{~N}_{18} \mathrm{O}_{209} \mathrm{Re}_{18} \mathrm{~S}_{24}: \mathrm{C}, 21.92 ; \mathrm{H}, 3.66 ; \mathrm{N}, 2.19 ; \mathrm{S}, 6.69$. Found: C, 22.0; H, 3.8; N, 2.1; S, 6.6. IR ( $\left.\mathrm{KBr}, \mathrm{cm}^{-1}\right): \mathrm{v}=3417(\mathrm{~s}), 2927(\mathrm{~m})$, $2121(s), 1639(w), 1419(w), 1371(w), 1338(w), 1303(w), 1244(w)$, $1159(\mathrm{~m}), 1105(\mathrm{w}), 1078(\mathrm{w}), 1024(\mathrm{~s}), 999(\mathrm{w}), 941(\mathrm{w}), 854(\mathrm{w}), 760$ (w), $707(w), 608(w), 583(w), 526(w), 409(w)$. EDS shows Re : S : K : Cs ratio $=18: 23.8: 7.9: 3.8$. Thermogravimetric analysis revealed a weight loss of about $7.7 \%$ from 50 to $200{ }^{\circ} \mathrm{C}$ (the theoretical weight loss of $49 \mathrm{H}_{2} \mathrm{O}$ is $7.67 \%$ ).

\section{Acknowledgements}

The authors address a special thank to N. B. Kompankov for technical support. The Authors gratefully acknowledge financial support from LIA-CNRS CLUSPOM and LabEx CHARMMMAT. This work was also supported by i) University of Versailles Saint Quentin, ii) CNRS, iii) Région lle de France through DIM Nano K, iv) the Czech Science Foundation ( $\left.N^{\circ} 18-05076 S\right)$, v) Russian Science Foundation (No. 15-15-10006), vi) Russian Foundation for Basic Research (grant number 17-53-16006), vii) NIIC thanks Federal Agency for Scientific Organizations for funding and viii) A.A. Ivanov thanks Embassy of France in Russia for the Vernadsky scholarship for post-graduate students

Keywords: metal cluster complex - cyclodextrin supramolecular self-assembly • luminescence • electrochemistry

[1] D. B. Walker, G. Joshi, A. P. Davis, Cell. Mol. Life Sci. 2009, 66, 3177 3179

[2] a) M. M. Boyle, R. A. Smaldone, A. C. Whalley, M. W. Ambrogio, Y. Y Botros, J. F. Stoddart, Chem. Sci. 2011, 2, 204-210; b) A. de la Escosura-Muñiz, A. Merkoçi, ACS Nano 2012, 6, 7556-7583.

[3] A. Magnuson, M. Anderlund, O. Johansson, P. Lindblad, R. Lomoth, T. Polivka, S. Ott, K. Stensjö, S. Styring, V. Sundström, L. Hammarström Acc. Chem. Res. 2009, 42, 1899-1909.

[4] A. J. Neel, M. J. Hilton, M. S. Sigman, F. D. Toste, Nature 2017, 543, 637-646.

[5] a) A. Müller, P. Gouzerh, Chem. Soc. Rev. 2012, 41, 7431-7463; b) R A. Smaldone, R. S. Forgan, H. Furukawa, J. J. Gassensmith, A. M. Z. Slawin, O. M. Yaghi, J. F. Stoddart, Angew. Chem.-Int. Ed. 2010, 49, 8630-8634.

[6] a) T. R. Cook, Y.-R. Zheng, P. J. Stang, Chem. Rev. 2013, 113, 734 777; b) J. Marrot, M. A. Pilette, M. Haouas, S. Floquet, F. Taulelle, X López, J. M. Poblet, E. Cadot, J. Am. Chem. Soc. 2012, 134, 1724 1737; c) Y. Molard, Acc. Chem. Res. 2016, 49, 1514-1523.

[7] F. Hapiot, H. Bricout, S. Menuel, T. S., E. Monflier, Catal. Sci. Technol. 2014, 4, 1899-1908.

[8] a) K. Benner, P. Klüfers, J. Schuhmacher, Angew. Chem.-Int. Ed. 1997 36, 743-745; b) M. O'Keeffe, O. M. Yaghi, Chem. Rev. 2012, 112, 675702.

[9] a) M. Chen, L. Cui, C. Li, G. Diao, J. Hazard. Mater. 2009, 162, 23-28; b) A. Harada, Y. Takashima, M. Nakahata, Acc. Chem. Res. 2014, 47, 2128-2140; c) E. Karakhanov, A. L. Maksimov, A. V. Zolotukhina, Y. S. Kardasheva, Russ. Chem. Bull. 2013, 62, 1465-1492; d) Z. Liu, A Samanta, J. Lei, J. Sun, Y. Wang, J. F. Stoddart, J. Am. Chem. Soc. 2016, 138, 11643-11653.

[10] R. Gramage-Doria, D. Armspach, D. Matt, Coord. Chem. Rev. 2013 257, 776-816.

[11] L. Leclercq, A. R. Schmitzer, Organometallics 2010, 29, 3442-3449.

[12] a) M. A. Moussawi, M. Haouas, S. Floquet, W. E. Shepard, P. A. Abramov, M. N. Sokolov, V. P. Fedin, S. Cordier, A. Ponchel, E. Monflier, J. Marrot, E. Cadot, J. Am. Chem. Soc. 2017, 139, 1437614379; b) M. A. Moussawi, N. Leclerc-Laronze, S. Floquet, P. A Abramov, M. N. Sokolov, S. Cordier, E. Monflier, H. Bricout, D. Landy, M. Haouas, J. Marrot, E. Cadot, J. Am. Chem. Soc. 2017, 139, 12793 12803; c) Y. Wu, R. Shi, Y.-L. Wu, J. M. Holcroft, Z. Liu, M. Frasconi, M. R. Wasielewski, H. Li, J. F. Stoddart, J. Am. Chem. Soc. 2015, 137, 4111-4118; d) L. Yue, S. Wang, D. Zhou, H. Zhang, B. Li, L. Wu, Nat 
Commun. 2016, 7, 10742-10752; e) B. Zhang, W. Guan, F. Yin, J. Wang, B. Li, L. Wu, Dalton Trans. 2018, 47, 1388-1392 ; f) B. Zhang, L. Yue, Y. Wang, Y. Yang, L. Wu, Chem. Commun. 2014, 50, 1082310826.

[13] a) P. A. Abramov, A. A. Ivanov, M. A. Shestopalov, M. A. Moussawi, E. Cadot, S. Floquet, M. Haouas, M. N. Sokolov, J. Clust. Sci. 2018, 29, 9 13; b) K. Kirakci, V. Šícha, J. Holub, P. Kubát, K. Lang, Inorg. Chem. 2014, 53, 13012-13018.

[14] a) M. Amela-Cortes, A. Garreau, S. Cordier, E. Faulques, J.-L. Duvail, Y. Molard, J. Mater. Chem. C 2014, 2, 1545-1552; b) M. Amela-Cortes, Y. Molard, S. Paofai, A. Desert, J. L. Duvail, N. G. Naumov, S. Cordier, Dalton Trans. 2016, 45, 237-245; c) O. A. Efremova, Y. A. Vorotnikov, K. A. Brylev, N. A. Vorotnikova, I. N. Novozhilov, N. V. Kuratieva, M. V. Edeleva, D. M. Benoit, N. Kitamura, Y. V. Mironov, M. A. Shestopalov, A. J. Sutherland, Dalton Trans. 2016, 45, 15427-15435; d) R. El Osta, A. Demont, N. Audebrand, Y. Molard, T. T. Nguyen, R. Gautier, K. A. Brylev, Y. V. Mironov, N. G. Naumov, N. Kitamura, S. Cordier, Z. Anorg. Allg. Chem. 2015, 641, 1156-1163; e) K. Kirakci, P. Kubát, K. Fejfarová, J. Martinčík, M. Nikl, K. Lang, Inorg. Chem. 2016, 55, 803-809; f) M. A. Mikhailov, K. A. Brylev, P. A. Abramov, E. Sakuda, S. Akagi, A. Ito, N. Kitamura, M. N. Sokolov, Inorg. Chem. 2016, 55, 8437-8445; g) L. Riehl, A. Seyboldt, M. Ströbele, D. Enseling, T. Jüstel, M. Westberg, P. R. Ogilby, H.-J. Meyer, Dalton Trans. 2016, 45, 15500-15506; h) M. N. Sokolov, K. A. Brylev, P. A. Abramov, M. R. Gallyamov, I. N. Novozhilov, N. Kitamura, M. A. Mikhaylov, Eur. J. Inorg. Chem. 2017, $4131-4137$.

[15] a) A. M. Cheplakova, A. O. Solovieva, T. N. Pozmogova, Y. A. Vorotnikov, K. A. Brylev, N. A. Vorotnikova, E. V. Vorontsova, Y. V. Mironov, A. F. Poveshchenko, K. A. Kovalenko, M. A. Shestopalov, J. Inorg. Biochem. 2017, 166, 100-107; b) E. V. Svezhentseva, A. O. Solovieva, Y. A. Vorotnikov, O. G. Kurskaya, K. A. Brylev, A. R. Tsygankova, M. V. Edeleva, S. N. Gyrylova, N. Kitamura, O. A. Efremova, M. A. Shestopalov, Y. V. Mironov, A. M. Shestopalov, New J. Chem. 2017, 41, 1670-1676.

[16] a) S.-J. Choi, K. A. Brylev, J.-Z. Xu, Y. V. Mironov, V. E. Fedorov, Y. S. Sohn, S.-J. Kim, J.-H. Choy, J. Inorg. Biochem. 2008, 102, 1991-1996 b) A. A. Krasilnikova, A. O. Solovieva, K. E. Trifonova, K. A. Brylev, A. A. Ivanov, S.-J. Kim, M. A. Shestopalov, M. S. Fufaeva, A. M. Shestopalov, Y. V. Mironov, A. F. Poveshchenko, L. V. Shestopalova, Contrast Media Mol. Imaging 2016, 11, 459-466.

[17] a) A. A. Krasilnikova, M. A. Shestopalov, K. A. Brylev, I. A. Kirilova, O. P. Khripko, K. E. Zubareva, Y. I. Khripko, V. T. Podorognaya, L. V. Shestopalova, V. E. Federov, Y. V. Mironov, J. Inorg. Biochem 2015 144, 13-17; b) A. A. Krasilnikova, A. O. Solovieva, A. A. Ivanov, K. E. Trifonova, T. N. Pozmogova, A. R. Tsygankova, A. I. Smolentsev, E. I. Kretov, D. S. Sergeevichev, M. A. Shestopalov, Y. V. Mironov, A. M. Shestopalov, A. F. Poveshchenko, L. V. Shestopalova, Nanomedicine: NBM 2017, 13, 755-763.

[18] a) A. Beltrán, M. Mikhailov, M. N. Sokolov, V. Pérez-Laguna, A. Rezusta, M. José Revillo, F. Galindo, J. Mater. Chem. B 2016, 4, 59755979; b) C. Felip-León, C. Arnau del Valle, V. Pérez-Laguna, M. I. Millán-Lou, J. F. Miravet, M. Mikhailov, M. N. Sokolov, A. RezustaLópez, F. Galindo, J. Mater. Chem. B 2017, 5, 6058-6064; c) A. O. Solovieva, Y. A. Vorotnikov, K. E. Trifonova, O. A. Efremova, A. A. Krasilnikova, K. A. Brylev, E. V. Vorontsova, P. A. Avrorov, L. V. Shestopalova, A. F. Poveshchenko, Y. V. Mironov, M. A. Shestopalov, J. Mater. Chem. B 2016, 4, 4839-4846.

[19] J. Szejtli, Med. Res. Rev. 1994, 14, 353-386.

[20] K. I. Assaf, M. S. Ural, F. Pan, T. Georgiev, S. Simova, K. Rissanen, D. Gabel, W. M. Nau, Angew. Chem.-Int. Ed. 2015, 54, 6852-6856.

[21] a) Y. V. Mironov, J. A. Cody, T. E. Albrecht-Schmitt, J. A. Ibers, J. Am. Chem. Soc. 1997, 119, 493-498; b) H.-J. Schneider, F. Hacket, V. Rüdiger, H. Ikeda, Chem. Rev. 1998, 98, 1755-1785.

[22] A. J. M. Valente, R. A. Carvalho, O. Söderman, Langmuir 2015, 31, 6314-6320.

[23] M. V. Rekharsky, Y. Inoue, Chem. Rev. 1998, 98, 1875-1917.

[24] T. Matsue, D. H. Evans, T. Osa, N. Kobayashi, J. Am. Chem. Soc. 1985, 107, 3411-3417.
[25] W. A. Rabanal-León, J. A. Murillo-López, D. Páez-Hernández, R. Arratia-Pérez, J. Phys. Chem. A 2014, 118, 11083-11089.

[26] T. Yoshimura, S. Ishizaka, Y. Sasaki, H.-B. Kim, N. Kitamura, N. G. Naumov, M. N. Sokolov, V. E. Federov, Chem. Lett. 1999, 28, 11211122.

[27] K. Lang, J. Mosinger, D. M. Wagnerová, Coord. Chem. Rev. 2004, 248, 321-350.

[28] A. O. Solovieva, K. Kirakci, A. A. Ivanov, P. Kubát, T. N. Pozmogova, S. M. Miroshnichenko, E. V. Vorontsova, A. V. Chechushkov, K. E. Trifonova, M. S. Fufaeva, E. I. Kretov, Y. V. Mironov, A. F. Poveshchenko, K. Lang, M. A. Shestopalov, Inorg. Chem. 2017, 56 13491-13499.

[29] a) H. Imoto, N. G. Naumov, A. V. Virovets, T. Saito, V. E. Federov, J Struct. Chem. 1998, 39, 720-727; b) N. G. Naumov, S. B. Artemkina, A V. Virovets, V. E. Fedorov, Solid State Sci. 1999, 1, 473-481; c) N. G. Naumov, A. V. Virovets, N. V. Podberezskaya, V. E. Federov, J. Struct. Chem. 1997, 38, 857-862.

[30] M. A. Delsuc, T. E. Malliavin, Anal. Chem. 1998, 70, 2146-2148.

[31] Oxford Diffraction. CrysAlis CCD and CrysAlis RED, including ABSPACK Versions 1.171.32.32006.

[32] G. M. Sheldrick, SADABS, program for scaling and correction of area detector data, University of Göttingen, Germany 1997.

[33] G. M. Sheldrick, Acta Cryst. C 2015, 71, 3-8.

[34] O. V. Dolomanov, L. J. Bourhis, R. J. Gildea, J. A. K. Howard, H. Puschmann, J. Appl. Cryst. 2009, 42, 339-341. 


\section{FULL PAPER}

\section{FULL PAPER}
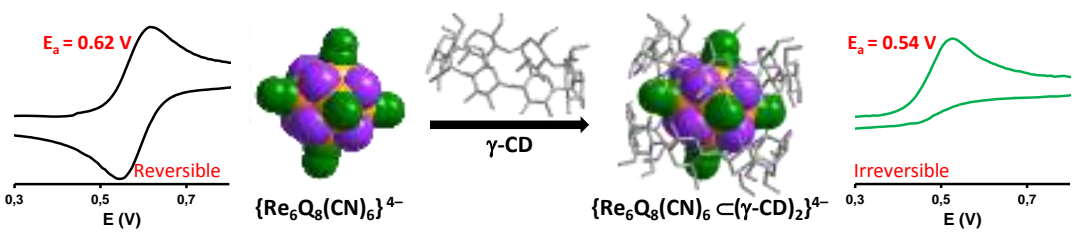

Supramolecular recognition dictated by chaotropic effect. Water-soluble $\left[\mathrm{Re}_{6} \mathrm{Q}_{8}(\mathrm{CN})_{6}\right]^{4-}(\mathrm{Q}=\mathrm{S}$, Se, Te $)$ octahedral clusters react with $\gamma$-cyclodextrin producing supramolecular inclusion systems. The nature of the inner $Q$ ligands influences strongly the water structure - breaking character of the clusters, resulting in different host-guest stability. The encapsulation modifies significantly the intrinsic physical-chemical properties of the inorganic guest (redox \& luminescence).
A.A. Ivanov, C. Falaise, P.A. Abramov, ${ }^{*}$ M.A. Shestopalov, K. Kirakci, K. Lang, M.A. Moussawi, M.N. Sokolov, N.G. Naumov, S. Floquet, D. Landy, M. Haouas, ${ }^{*}$ K.A. Brylev, Y.V. Mironov, Y. Molard, S. Cordier and E. Cadot*

Page No. - Page No.

Host-Guest Binding Hierarchy within Redox- and Luminescence Responsive Supramolecular SelfAssembly Based on Chalcogenide Clusters and $\gamma$-Cyclodextrin 